\title{
A Socio-Ecological Approach to Improve Industrial Zones Towards Eco- Industrial Parks
}

\author{
(Pre-print Article)
}

\author{
Genc, O., van Capelleveen, G., Erdis, E., Yildiz, O. \& Yazan, D. M., \\ 15 Nov 2019 \\ In: Journal of environmental management. 250, 109507. \\ DOI: $10.1016 /$ j.jenvman.2019.109507 \\ URL: https://doi.org/10.1016/j.jenvman.2019.109507
}

\begin{abstract}
One of the concrete examples of industrial symbiosis development is eco-industrial parks, which improves resource efficiency and minimizes environmental impacts by adopting models for waste exchanges between industries. Despite past efforts, many industrial zones around the world are not yet considered as eco-industrial parks because of the low number (or total lack) of symbiotic relationships among industries. A promising strategy is to develop those existing industrial zones into eco-industrial parks. However, there is a lack of studies addressing how to assess the environmental improvement in relation to network sustainability. This study demonstrates such an assessment approach using an integration of food web analysis and social network analysis. These two methods can assist in assessing differences in network configurations with respect to potential implementations of industrial symbiosis, and in analysing the resilience, redundancy, connectance, and cyclicity of eco-parks. The use of the methods is illustrated in a case study of an industrial zone in Turkey. Four potential future scenarios are proposed including potential future co-location of companies in the industrial zone in order to foster industrial symbiotic network formation. These scenarios are compared with the current configuration. The results indicate the method's ability to assess the resilience of an industrial network. Moreover, the case shows an improvement of network sustainability and follows some sustainable properties of natural ecosystems as a result of implementing the industrial symbiosis.
\end{abstract}

Key words: Industrial symbiosis, eco-industrial parks, circular economy, social network analysis, food web analysis

\section{INTRODUCTION}

The rapid exhaustion of non-renewable Earth resources incited society to search for alternative sources and methods to use in industrial processes. Biology is slowly yielding lessons and recommendations for technology that address sustainability concerns, but innovations are not rapid enough to compensate the rising depletion of resources (Vincent, 2017). If society is able to understand the order of the nature that has sustainably existed for many years, it may derive functional concepts and apply them in product and production network development in order to establish a more sustainable environment. This type of sustainable thinking is captured in the concept of a circular economy (CE), which aims to keep resources in use for as long as possible to derive the maximal value from them while in use, then reclaim and 
reproduce products and materials at the end of each usable life.

One of the key strategies contributing towards the CE is industrial symbiosis (IS). IS is a sub-branch of industrial ecology that connects different industries by the transaction of material, energy or physical exchange of services with the aim to obtain economic and competitive advantage in an environmentally and socially sustainable manner (Chertow, 2000). IS is closely related to creating relations among companies to increase the sustainability and efficiency of material and energy flows through the entire production processes (Ehrenfeld and Gertler, 1997).

Although self-organizing industrial symbiosis networks (ISNs) have been noticed to produce many advantages over the last decades, some IS implementations are developed in eco-industrial parks (eco-parks) (Chertow, 2007, 2000). In essence, ecoparks are a networked evolution of IS, which results from the directed effort to identify firms from different sectors with a plan to locate them together in order to stimulate resources sharing among tenant plants (Chertow and Ehrenfeld, 2012)

Despite the considerable efforts, many of the industrial zones (IZs) around the world do not meet the environmental standards to be classified as eco-parks, in particular because of the low number (or total lack) of symbiotic relationships among industries and the absence of addressing the environmental issues in a comprehensive way within those IZs (Côté and Cohen-Rosenthal, 1998; Sakr et al., 2011). To reach this potential, parks can either be redesigned from scratch or existing parks can be transformed into eco-parks (Chertow, 2007; Boons et al., 2017). Implementing a theoretically designed eco-park is conceded with many risks such as the variety of optimization objectives of participants and the operational uncertainties (Kuznetsova et al., 2016). Moreover, developing a park from scratch is costly. Alternatively, the strategy to transform existing parks into eco-parks is mostly more viable (e.g., the National Industrial Symbiosis Program (NISP), (Paquin and Howard-Grenville, 2012) and Eco-Town programs, (Van Berkel et al., 2009)). Such solutions either evolve from the discovery of new symbiotic relationships or from a reconfiguration of industries within the existing IZs (Afshari et al., 2018).

Evaluation methods are needed to measure the achievement of improved sustainability when transforming IZs into eco-parks. Many methods are yet in place for measuring the environmental output (e.g. $\mathrm{CO}_{2}, \mathrm{NO}_{x}, \mathrm{SO}_{2}$ ) of a potential IS during its development phase (e.g., life-cycle analysis tools) (Grant et al., 2010; van Capelleveen et al., 2018) and for long-term monitoring of an entire eco-park (e.g., using sustainability scorecards) (Buys et al., 2014). However, only few studies address the aspects of network sustainability (i.e., to retain the environmental, economic and social benefits of a new park configuration).

Food webs analysis (FWA) can illustrate the relations between eco-parks and biological food webs (Hardy and Graedel, 2002; Layton et al., 2016; Malone et al., 2018; Reap and Bras, 2014). The FWA method relies on the industrial ecosystem analogy, which suggests that there are underlying similarities between biological and industrial colonies (Wright et al., 2009). This analogy can be applied to industrial ecosystems to measure ecological sustainability (Allenby and Cooper, 1994; Graedel, 1996; Tiejun, 2010). Food webs portray the feeding connections between producers (preys) and consumers (predators) in natural ecosystems, and are the most 
extensively recognized representation of the relationships between species. Many of the properties of food webs can be beneficial from both economic and industrial perspectives, and could positively influence resulting emissions, costs, and process efficiency (Layton, 2014; Reap, 2009).

Social network analysis (SNA) is suggested as one of the evaluation methodologies that can capture improvements on network sustainability with indicators characterized by the network configuration (Vázquez et al., 2018). SNA is a tool that can help to identify key actors in networks and is one of the effective methods to analyse social relationships in industrial networks to develop actions that can strengthen resilience in the network (Domenech and Davies, 2009; Song et al., 2018). For example, SNA is effectively used as a method to analyse ISNs with respect to relationships between participant companies's managers (Ashton, 2008), relationships among companies's goals and indicators (Sebestyén et al., 2019) relationships among tenant firms (Song et al., 2018), and to compare exchanges of products, by-products, and wastes among tenant plants (Zhang et al., 2013).

Previous studies outline that both FWA and SNA are effective methods to monitor and evaluate the states of existing eco-parks. However, the literature lacks to address the potential strength of integration both methods for assessing changes in network sustainability when developing an eco-park, i.e., improving an existing conventional industrial zone (IZ) towards an eco-park by implementing discovered or identified symbiotic opportunities. This paper proposes the integration of FWA and SNA, by means of making a combined interpretation on the results from both evaluation methods, as an effective approach for assessing the sustainability of future configurations of ISNs. The quantitative data on the waste streams of an IZ are used to demonstrate the integrated FWA and SNA method to assess the sustainability of implementable IS relationships in the network, and to show the resilience, redundancy, connectance and cyclicity of the proposed future eco-park designs.

The remaining of this paper is organized as follows. Section 2 presents the methodology used in this study. Section 3 presents the investigated case study including scenarios for potential future symbiotic opportunities. Section 4 presents an evaluation of the current IZ configuration and the four potential future scenarios of the IZ by presenting the results from the FWA and SNA. Section 5 provides a discussion based on the results, and finally, Section 6 draws the conclusions.

\section{METHODOLOGY}

This study analyses network differences with respect to implementable industrial symbiosis (IS) businesses by means of food web analysis (FWA) and social network analysis (SNA) to measure the resilience, redundancy, connectance, and cyclicity of industrial zones (IZs). A case study approach is adopted at one of the IZs in Turkey. The IZ's waste flow network realized in 2015 is referred as the base case. The base case is compared with four potential future waste flow network scenarios in which identified symbiotic relationships are hypothetically implemented in the scenarios to evaluate the evolving state of the IZ.

The evaluation methods for analysing sustainability of the IZ's existing and potential future networks are addressed in the following subsections. Section 2.1 captures an 
explanation of the FWA method and its particular metrics employed in this study followed by Section 2.2 that similarly describes the method of SNA and its metric definitions used in this study.

\subsection{Food Web Analysis}

In many fields, biomimicry, which is defined by Benyus (2002) as innovation inspired by nature, has recently gained great attention. From an industrial point of view, this approach shows itself as food webs, which may be a natural model in the transition from a linear to a circular economy (CE). Food webs show interactions among organisms in an ecosystem, while food chains are linear representations of energy flow (Odum, 1969). Therefore, food webs are a more realistic portrayal of the energy flow in an ecosystem (Layton, 2014). The materials and energy flows in a natural ecosystem can be represented in a food web matrix [F] (Layton et al., 2017) as shown in Figure 1. Such matrix contains the prey-predator relations between species. A species in an ecosystem can be both prey and predator. Therefore, $[\mathrm{F}]$ will be a square matrix.

In this part of the study, it is assumed that biological food webs are inherently sustainable and mimicking their properties will bring ISNs closer to the sustainable functioning of nature. The main validity of this assumption is based on a study carried by Reap (2009) showing a relationship between a traditionally optimized carpetrecycling network and the same carpet-recycling network designed by mimicking the properties of natural food webs. In symbiotic relationships, the quality and amount of the exchanging wastes/by products are important features. As food web matrix $[\mathrm{F}]$ is concerned only with the structural information such as links (relations) and nodes (plants) of a network, it is blind to information such as flow magnitude, rate and quality. Therefore, it is also assumed that the wastes/by products used to create potential future scenarios are sufficient to establish symbiotic relationships in terms of quality and amount.

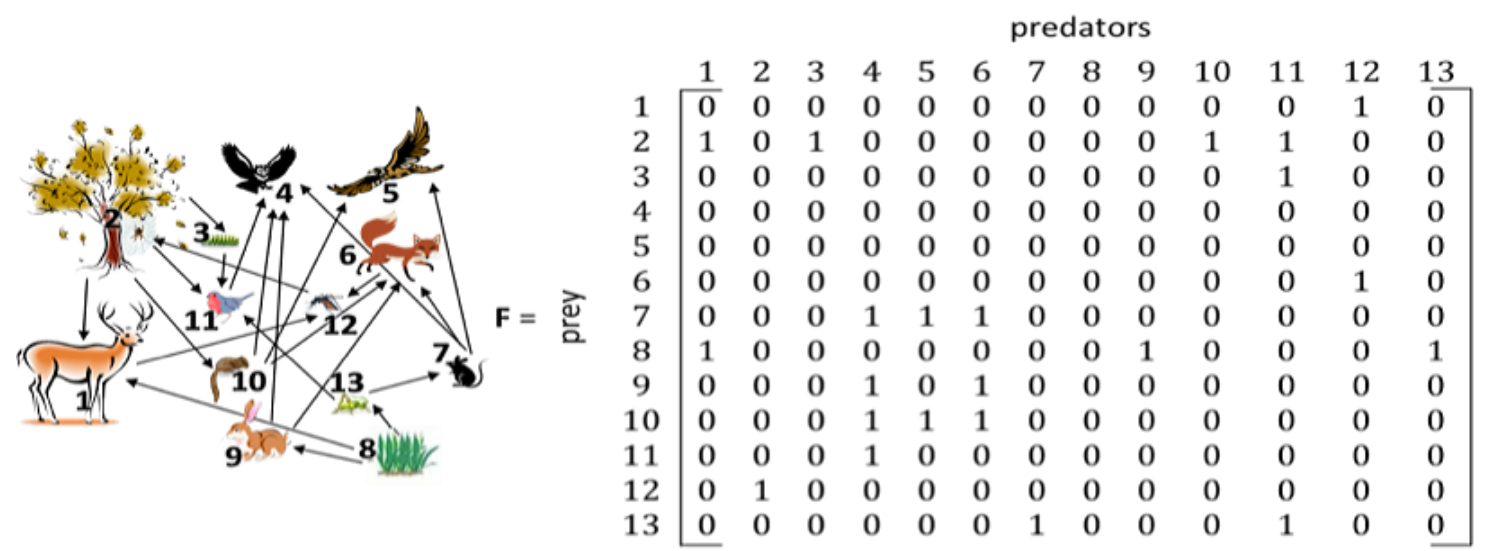

Fig. 1. Left - A food web of a hypothetical ecosystem with species numbered (Arrows point at predators). Right $-\mathrm{A}$ food web matrix $[\mathrm{F}]$; fij $=1$ represents a unidirectional link between prey (i) and predator $(\mathrm{j}$ ) and a zero represent no link (where $i=0,1, \ldots, \mathrm{m}$ and $j=0,1, \ldots, \mathrm{n}$ ). Adapted from Layton et al. (2017) with permission.

Waste producer and receiver plants in the IZ are represented as preys and predators respectively. A food web matrix [F], which represents waste flows between plants, is 
defined for the base case and four potential future scenarios. Details of the food web matrices for the base case and four potential future scenarios are available in the Supporting Information-S1.

\subsubsection{Food Web Metrics}

Ecologists use structural metrics to analyse ecological food webs. Network compositions using these metrics meet the traditional network design objectives of reduced cost and emissions and increased efficiency (Reap, 2009). The food web metrics used in this study are explained below.

Species Richness $\left(\mathbf{S}_{\mathbf{R}}\right)$ : Species richness $\left(\mathrm{S}_{\mathrm{R}}\right)$ is the total number of species in a natural ecosystem, and it is the simplest way to describe regional diversity (Gotelli and Colwell, 2001). In this study, $S_{R}$ represents the total number of plants within the IZ.

Number of Links $\left(\mathbf{N}_{\mathbf{L}}\right)$ : The total number of direct relations between species in a food web, and it is represented by the nonzero interactions in $[\mathrm{F}]$. In this study, number of links $\left(\mathrm{N}_{\mathrm{L}}\right)$ represents the number of direct waste flows between plants within the IZ, and it is calculated as shown by Equation 1 .

$\mathrm{N}_{\mathrm{L}}=\sum_{\mathrm{i}=1}^{\mathrm{m}} \sum_{\mathrm{j}=1}^{\mathrm{n}} \mathrm{f}_{\mathrm{ij}}$

Link Density $\left(\mathbf{L}_{\mathbf{D}}\right)$ : Link density $\left(\mathrm{L}_{\mathrm{D}}\right)$ is the average number of flows into or out of each species (Ulanowicz et al., 2014). In this study, $L_{D}$ represents the average number of waste flow per plant within the IZ, and it is calculated as shown by Equation 2.

$\mathrm{L}_{\mathrm{D}}=\frac{\mathrm{N}_{\mathrm{L}}}{\mathrm{S}_{\mathrm{R}}}$

Prey ( $\left.\mathbf{N}_{\text {prey }}\right)$ : Prey is a species consumed by other species in a biological ecology (Hardy and Graedel, 2002). In this study, preys represent the waste producer plants in the IZ, and the total number of prey $\left(\mathrm{N}_{\text {prey }}\right)$ is calculated as shown by Equation 3 and 4. Note that each plant within the IZ produces wastes. When $\mathrm{N}_{\text {prey }}$ and its related food web metrics are calculated, only those plants that send their wastes to another plant located within the IZ are counted as waste producers.

$$
f_{r}(i)=\left\{\begin{array}{l}
0 \text { for } \sum_{j=1}^{n} f_{i j}=0 \\
1 \text { for } \sum_{j=1}^{n} f_{i j}>0
\end{array}\right.
$$




$$
\mathrm{N}_{\text {prey }}=\sum_{\mathrm{i}=1}^{\mathrm{m}} \mathrm{f}_{\mathrm{r}}(\mathrm{i})
$$

where $f_{r}$ is the number of rows containing minimum one value greater than 0 in $[F]$.

Predator ( $\mathbf{N}_{\text {predator): }}$ Predator is a species that consume other species in a biological ecology (Hardy and Graedel, 2002). In this study, predators represent the waste receiver plants within the IZ, and the total number of predator $\left(\mathrm{N}_{\text {predator }}\right)$ is calculated as shown by Equation 5 and Equation 6 .

$$
\begin{aligned}
& f_{c}(j)=\left\{\begin{array}{l}
0 \text { for } \sum_{i=1}^{m} f_{i j}=0 \\
1 \text { for } \sum_{i=1}^{m} f_{i j}>0
\end{array}\right. \\
& N_{\text {predator }}=\sum_{j=1}^{n} f_{c}(j)
\end{aligned}
$$

where $f_{c}$ is the number of columns containing minimum one value greater than 0 in $[\mathrm{F}]$.

Prey to Predator Ratio $\left(\mathbf{P}_{\mathbf{r}}\right)$ : The ratio of the number of preys to the number of predators. In this study, prey to predator ratio $\left(\mathrm{P}_{\mathrm{r}}\right)$ represents the ratio of the number of waste producer plants to waste receiver plants within the IZ, and calculated as shown by Equation 7.

$$
\mathrm{P}_{\mathrm{r}}=\frac{\mathrm{N}_{\text {prey }}}{\mathrm{N}_{\text {predator }}}
$$

Generalization $(\mathbf{G})$ : Average number of prey consumed per predator in a food web (Reap, 2009). In this study, generalization (G) represents the number of waste producer plants interacted per receiver plant within the IZ and calculated as shown by Equation 8.

$$
\mathrm{G}=\frac{\mathrm{N}_{\mathrm{L}}}{\mathrm{N}_{\text {predator }}}
$$

Vulnerability (V): Average number of predator per prey in a food web (Reap, 2009). In this study, vulnerability (V) represents the number of waste receiver plants per waste producer plant within the IZ and calculated as shown by Equation 9.

$$
\mathrm{V}=\frac{\mathrm{N}_{\mathrm{L}}}{\mathrm{N}_{\text {prey }}}
$$

Connectance (C): Connectance $(C)$ is the fraction of pairs of species that directly 
interact; in other words, the average strength of interspecies interactions in an ecosystem (Yodzis, 1980). In this study, C represents the number of direct waste flows within the IZ divided by the total number of theoretically possible flows. $\mathrm{C}$ is calculated as shown by Equation 10, and Equation 11 if self-loop is considered.

$$
\begin{aligned}
& C=\frac{N_{L}}{S_{R}\left(S_{R}-1\right)} \\
& C=\frac{N_{L}}{S_{R}^{2}}
\end{aligned}
$$

Cyclicity $\left(\lambda_{\max }\right)$ : Cyclicity $\left(\lambda_{\max }\right)$ is the measure of the strength of structural cycling in a food web, and it is given by the maximum real eigenvalue of the structural adjacency matrix $[\mathrm{A}]$, where the transpose of the $[\mathrm{F}]$ is the adjacency matrix (Bras et al., 2016; Fath and Halnes, 2007). Cyclicity helps understanding contrariety between the natural and industrial systems (Layton et al., 2013). Cyclicity can be either 0 (no internal cycling), 1 (weak internal cycling) or greater than 1 (strong internal cycling) (Fath and Halnes, 2007; Morris et al., 2018). This is illustrated in Figure 2. $\lambda_{\max }$ is calculated as shown by Equation 12:

$$
\operatorname{det}(\mathrm{A}-\lambda \mathrm{I})=0
$$

where $\mathrm{A}$ is the adjacency matrix, $\lambda$ are the eigenvalues, and $\mathrm{I}$ is the identity matrix.

a)

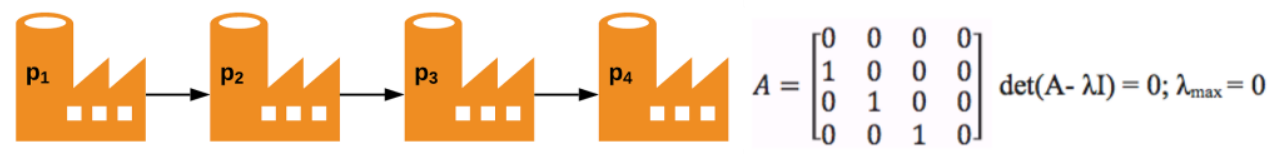

b)

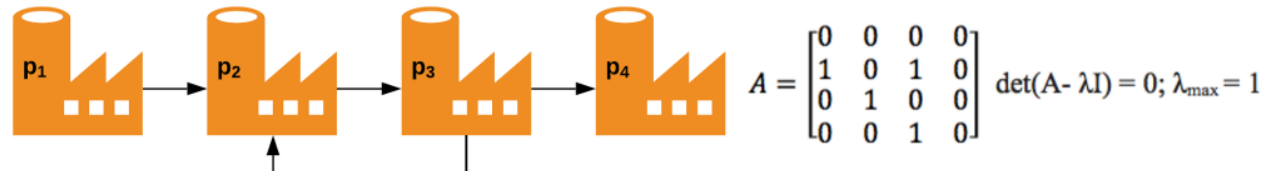

c)

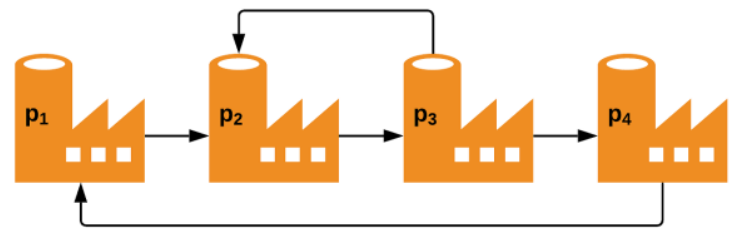
$A=\left[\begin{array}{llll}0 & 0 & 0 & 1 \\ 1 & 0 & 1 & 0 \\ 0 & 1 & 0 & 0 \\ 0 & 0 & 1 & 0\end{array}\right] \operatorname{det}(\mathrm{A}-\lambda \mathrm{I})=0 ; \lambda_{\max }=1,27$

Fig. 2. The three types of internal cycling based on cyclicity. a) No cycling, b) Weak cycling, and c) Strong cycling. Arrows point at predators (waste receivers). Inspired by Fath et al. (2007)

\subsection{Social Network Analysis}

A network, which is also called a graph, is a set of vertices with other name nodes, with connections between them, called edges or ties (Newman, 2003). A network can be directed or undirected based on the relationships between two nodes. SNA is not a formal theory in sociology (Otte and Rousseau, 2002) but it has attracted big interest recently, largely because of its likely relevance to diverse processes (Kossinets and 
Watts, 2006), and the methodology has been employed in many fields from psychology to economics (Borgatti et al., 2009).

\subsubsection{Social Network Metrics}

Two centrality metrics are used in this study: (1) degree centrality (based on the indegree and out-degree), and (2) betweenness centrality. These metrics provide information with respect to the most central nodes in a system based on different structural properties of a network such as neighborhood relations and shortest path analysis (Barrat et al., 2004). To visualize and analyse the base case and four potential future scenarios, the food web matrices $[\mathrm{F}]$, which are defined for the base case and four potential future scenarios, are also used in SNA as an adjacency matrix representing the structures and interactions in the networks. The SNA metrics used in this study are explained below.

Degree (D): Degree (D) shows the total number of edges connected to a node. A directed network has both an in-degree and an out-degree for each node, which are the numbers of incoming and out-going edges respectively (Newman, 2003). In this study, in-degree $\left(\mathrm{D}_{\mathrm{Nin}}\right)$ and out-degree $\left(\mathrm{D}_{\mathrm{Nout}}\right)$ represents the wastes received by and sent from a plant $\mathrm{N}$ respectively, and the total degree of a plant $\left(\mathrm{D}_{\mathrm{N}}\right)$ is calculated by summing the values of in-degrees and out-degrees as shown by Equation 13, and 14 if self-loop is considered. Figure 3 shows an example of a directed network.

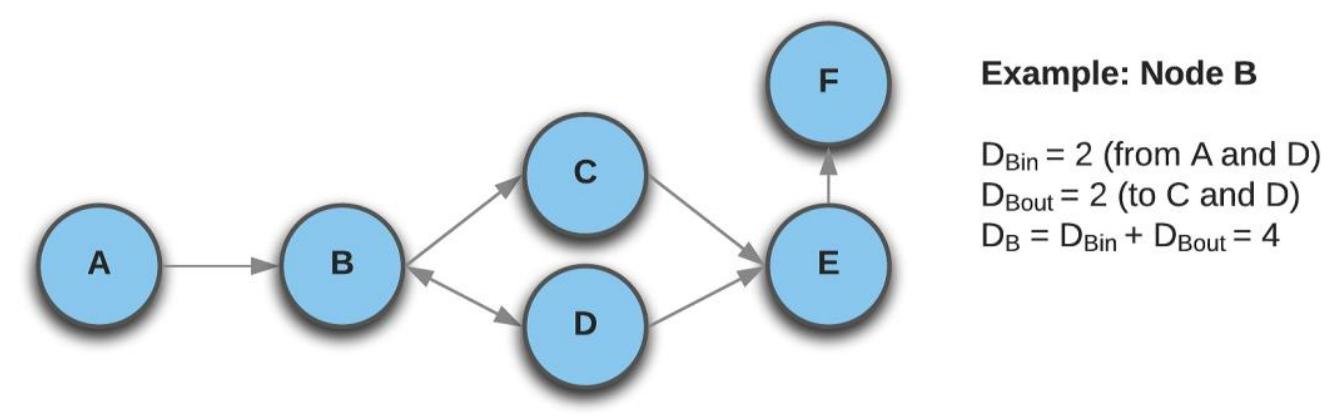

Fig. 3. A directed network (Arrows point at the receiver).

In this study, it is assumed that there is one directional edge from one node to another. For instance; if plant A sends two types of wastes to plant B, when plant A's out degree and plant B's in-degree are calculated, the multiple edges are counted once $\left(D_{\text {Aout }}=1, D_{B i n}=1\right)$. In the same way, if plant $C$ uses its own waste $\mathrm{k}$ as input (selfloop), the value of 1 is added to the plant's in-degree and out-degree. However, when plant C's total degree $\left(\mathrm{D}_{\mathrm{C}}\right)$ is calculated, either in-degree or out-degree is considered instead of summing them $\left(\mathrm{D}_{\mathrm{C}}=1\right)$.

$$
D_{N_{i}}=\sum_{i \neq j}^{N} D_{i n}+\sum_{i \neq j}^{N} D_{\text {out }}
$$




$$
\mathrm{D}_{\mathrm{N}_{\mathrm{i}}}=\sum_{\mathrm{i}}^{\mathrm{N}} \mathrm{D}_{\text {in }}+\sum_{\mathrm{i}}^{\mathrm{N}} \mathrm{D}_{\text {out }}
$$

Betweenness Centrality (BC): The betweenness centrality (BC) of a node is the sum of the minimum path lengths between that node and all other nodes (Freeman, 1977). A plant with high BC has impact and control on the exchange of wastes through an industrial network (Song et al., 2018). When calculating the betweenness centrality of a node $\mathrm{k}$, a normalization can be performed without a loss of precision by dividing through by the number of pairs of nodes not including $\mathrm{k}$, so that $\mathrm{BCk} \in[0,1]$. This scale is for the highest theoretical possible value, where one node is crossed by every single shortest path. In this study, BC reflects the relationships (like friendship) between the plants. Therefore, when the $\mathrm{BC}$ values are calculated, the networks are assumed as undirected (if $\mathrm{A}$ is a friend of $\mathrm{B}$ then $\mathrm{B}$ is a friend of $\mathrm{A}$ as well). The betweenness centrality of a node $\mathrm{k}$ is calculated as shown by Equation 15 .

$$
\mathrm{BC}_{\mathrm{k}}=\frac{2 \times \sum_{\mathrm{k} \neq \mathrm{i} \neq \mathrm{j}} \frac{\sigma_{\mathrm{ij}}(\mathrm{k})}{\sigma_{\mathrm{ij}}}}{(\mathrm{N}-1)(\mathrm{N}-2)}
$$

where $\sigma_{\mathrm{ij}}$ is the total number of shortest paths from node $\mathrm{i}$ to node $\mathrm{j}, \sigma_{\mathrm{ij}}(\mathrm{k})$ is the number of those paths that pass through node $\mathrm{k}$, and $\mathrm{N}$ is the number of nodes in the network.

Degree Centrality (DC): The total degree of a node is its degree centrality (DC) as well. The normalized degree centrality of a node can be calculated by dividing that node's total degree by the maximum theoretical possible connections the node can get (Everett and Borgatti, 1999). If two nodes have both an in-degree and an out-degree relation with each other, i.e., plant $\mathrm{A}$ sends waste to plant $\mathrm{B}$, and plant $\mathrm{B}$ also sends waste to plant $A$, only one-way relation is counted to calculate the plants's total degree $\left(D_{A}=D_{B}=1\right)$, and then $D C$ is calculated. For the degree centrality, higher values mean that the node is more central, but this does not always mean that the node is always in the center of the network (Golbeck, 2015). Hence, degree centrality reflects a node's ability to connect to other nodes rather than its influence on controlling them. DC is calculated as shown by Equation 16, and Equation 17 if self-loop is considered.

$$
\begin{aligned}
\mathrm{DC}_{\mathrm{N}_{\mathrm{i}}} & =\frac{\sum_{\mathrm{j}=1}^{\mathrm{N}} \mathrm{x}_{\mathrm{ij}}}{\mathrm{N}-1}, \mathrm{i} \neq \mathrm{j} \\
\mathrm{DC}_{\mathrm{N}_{\mathrm{i}}} & =\frac{\sum_{\mathrm{j}=1}^{\mathrm{N}} \mathrm{x}_{\mathrm{ij}}}{\mathrm{N}}
\end{aligned}
$$

\section{CASE STUDY}

For this case study, anonymized data, which belongs to one of the Industrial Zones (IZs) in Turkey, is used. The data is obtained by private sector plant visits and support of public institutions. The data set contains registered waste transactions realized in 2015. This includes types, producers, receivers and treatment/disposal processes of 
the wastes. The industry branches of the plants in the IZ also exist within the data. The industry branches are coded following the classification of economic activities in the European Union (NACE), and waste types are coded following the European Waste Catalogue (EWC). The IZ's waste flow network existed in 2015 is referred as the base case. The base case is compared with four potential future waste flow scenarios in which discovered symbiotic relationships are hypothetically implemented to evaluate the improvement opportunity of the IZ towards an eco-park.

Plants in the IZ are represented as nodes within a network, and edges between the nodes represent waste exchanges between the plants. A waste flow network model X $=(\mathrm{N}, \mathrm{L})$, where $\mathrm{X}$ is the symbiotic network, $\mathrm{N}$ are nodes, and $\mathrm{L}$ are edges, is defined for each dataset representing the base case and four potential future scenarios of the IZ. The datasets are described below:

Dataset 1: $\mathrm{N}=\left(\mathrm{n}_{1}, \mathrm{n}_{2}, \ldots, \mathrm{n}_{\mathrm{i}}\right)(\mathrm{i}=1,2, \ldots, 58)$ express that the IZ contains 58 industrial plants; $\mathrm{L}=\left(\mathrm{l}_{12}, \mathrm{l}_{13}, \ldots, \mathrm{l}_{\mathrm{ij}}\right)(\mathrm{i}, \mathrm{j}=1,2, \ldots, 58)$ express all the edges between different nodes. Dataset 1 reflects the base case.

Dataset 2: $\mathrm{N}=\left(\mathrm{n}_{1}, \mathrm{n}_{2}, \ldots, \mathrm{n}_{\mathrm{i}}\right)(\mathrm{i}=1,2, \ldots, 58)$ express that the IZ contains 58 industrial plants; $\mathrm{L}=\left(1_{12}, \mathrm{l}_{13}, \ldots, \mathrm{l}_{\mathrm{ij}}\right)(\mathrm{i}, \mathrm{j}=1,2, \ldots, 58)$ express all the edges between different nodes. Dataset 2 reflects the potential Future Scenario 1 for the IZ.

Dataset 3: $\mathrm{N}=\left(\mathrm{n}_{1}, \mathrm{n}_{2}, \ldots, \mathrm{n}_{\mathrm{i}}\right)(\mathrm{i}=1,2, \ldots, 58)$ express that the IZ contains 58 industrial plants; $\mathrm{L}=\left(\mathrm{l}_{12}, \mathrm{l}_{13}, \ldots, \mathrm{l}_{\mathrm{ij}}\right)(\mathrm{i}, \mathrm{j}=1,2, \ldots, 58)$ express all the edges between a single node (self-loop) or any pair of nodes. Dataset 3 reflects the potential Future Scenario 2 for the IZ.

Dataset 4: $\mathrm{N}=\left(\mathrm{n}_{1}, \mathrm{n}_{2}, \ldots, \mathrm{n}_{\mathrm{i}}\right)(\mathrm{i}=1,2, \ldots, 66)$ express that the IZ contains 66 industrial plants; $\mathrm{L}=\left(\mathrm{l}_{12}, \mathrm{l}_{13}, \ldots, \mathrm{l}_{\mathrm{ij}}\right)(\mathrm{i}, \mathrm{j}=1,2, \ldots, 66)$ express all the edges between different nodes. Dataset 4 reflects the potential Future Scenario 3 for the IZ.

Dataset 5: $\mathrm{N}=\left(\mathrm{n}_{1}, \mathrm{n}_{2}, \ldots, \mathrm{n}_{\mathrm{i}}\right)(\mathrm{i}=1,2, \ldots, 66)$ express that the IZ contains 66 industrial plants; $\mathrm{L}=\left(\mathrm{l}_{12}, \mathrm{l}_{13}, \ldots, \mathrm{l}_{\mathrm{ij}}\right)(\mathrm{i}, \mathrm{j}=1,2, \ldots, 66)$ express all the edges between a single node (self-loop) or any pair of nodes. Dataset 5 reflects the potential Future Scenario 4 for the IZ.

In this study, Gephi 0.9.2 is selected as SNA tool due to its rich analysis options and ease of use (Bastian and Heymann, 2009). The FWA calculations are performed in MS Excel 2011 and Wolfram Mathematica 11.

\subsection{Base Case}

The IZ has 58 plants in various industrial branches. There are 271 waste transactions in which the tenant plants of the IZ participated. However, only 32 of those 271 waste transactions are realized with partners within the IZ. Two plants implemented a form of industrial symbiosis (ST6 and ST16), all other transaction concern a disposal to recyclers (RE5, TE5, and P8). Figure 4 shows the waste flows within the IZ. Details of the existing plants with respect to their NACE Industrial Branches and NACE codes are available in the Supporting Information-S2. 


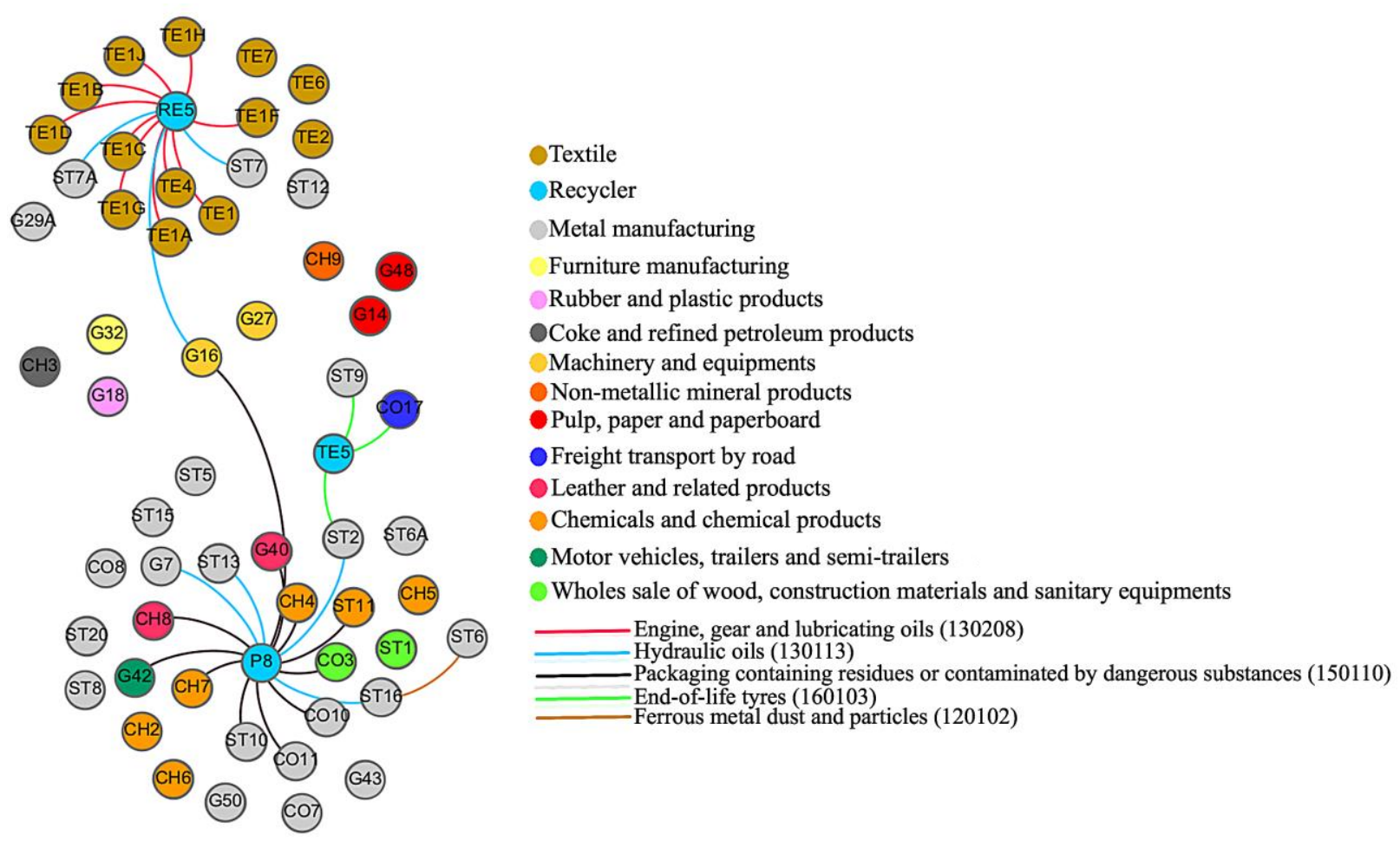

Fig. 4. Waste flows within the IZ

Note: The nodes represent the plants, and the edges represent the wastes. The waste flow direction (from producer to receiver) is indicated by the clockwise direction of a graph (there is no anticlockwise flow). See Supporting Information-S4 for grey scale version.

\subsection{Scenario Setting}

There are 14 types of wastes, which are produced by the plants operating within the IZ, suitable for industrial symbiosis (IS). However, these wastes are not adopted for IS businesses within the IZ yet. These wastes are either received by a recycler/disposer firm operating within or out of the IZ. None of the plants operating within the IZ is using inputs from any recycler firm in their production process. Therefore, none of those wastes, which are produced by plants located within the IZ and sent to any recycler, return to a plant within the IZ after treatment. The potential symbiotic relationships related to above-mentioned 14 wastes are identified from a database developed by the Centre for Industrial Sustainability, University of Cambridge. The database contains the library of IS case studies and linked exchanges gathered from publicly available sources (scientific papers, etc.), and has been developed as part of the activities of an EU funded project, MAESTRI, energy and resource management systems for improved efficiency in the process industries (Evans et al., 2017). For each symbiotic exchange in the database, the industrial sector 
of the plants involved, i.e., waste producers (donors) and waste receivers, is identified using the NACE code, while the exchanged material is identified using the EWC code. From now on, the MAESTRI database will be referred to as "symbiosis database'.

Out of those 14 types of wastes suitable for IS, 6 types have already potential receivers located within the IZ while 8 types have not yet. Scenario 1 and 2 are associated to the potential symbiotic relationship implementation for those 6 types of wastes with only existing receivers within the IZ. To understand how the 8 types of wastes can be used, colocation of new plants in the zone is considered in Scenario 3 and 4 . The list of considered implementable symbiotic relations used to construct these potential future scenarios are displayed in Table 1.

Table 1. Implementable symbiotic relations used to create potential future scenarios for the IZ

\begin{tabular}{|c|c|c|c|c|c|c|}
\hline Case & $\begin{array}{l}\text { Waste } \\
\text { (EWC } \\
\text { Code) }\end{array}$ & $\begin{array}{l}\text { EWC Code } \\
\text { Description }\end{array}$ & Providing Industries (NACE Code(s)) & $\begin{array}{l}\text { Potential Receiving } \\
\text { Industries (NACE } \\
\text { Code(s)) }\end{array}$ & $\begin{array}{l}\text { There is (a) potential } \\
\text { receiver(s) located } \\
\text { within the IZ }\end{array}$ & Scenario \\
\hline 1 & 100202 & Steel slag & $24.10 / 24.20$ & 20.13 & Yes & $1,2,3,4$ \\
\hline 3 & 200126 & Oil and fat & $13.10 / 24.10 / 24.20 / 25.93 / 28.29$ & 19.20 & Yes & $1,2,3,4$ \\
\hline 4 & 200139 & Plastics & $24.10 / 24.20 / 28.29$ & 24.10 & Yes & $1,2,3,4$ \\
\hline 7 & 040222 & $\begin{array}{l}\text { Wastes from } \\
\text { processed textile } \\
\text { fibres }\end{array}$ & 13.10 & 32.40 & No & 3,4 \\
\hline 8 & 120101 & $\begin{array}{l}\text { Ferrous metal filings } \\
\text { and turnings }\end{array}$ & $24.20 / 24.34 / 25.30 / 25.62 / 25.93 / 31.01$ & 24.40 & No & 3,4 \\
\hline 9 & 150101 & $\begin{array}{l}\text { Paper and cardboard } \\
\text { packaging }\end{array}$ & $19.20 / 20.14 / 23.64 / 24.10 / 24.20 / 25.30 / 28.29 / 38.32$ & $17.12 / 23.43$ & No & 3,4 \\
\hline 13 & 200101 & Paper and cardboard & $13.10 / 24.20 / 28.29$ & $01.13 / 17.10 / 17.29$ & No & 3,4 \\
\hline 14 & 200138 & Wood & 24.20 & 17.29 & No & 3,4 \\
\hline
\end{tabular}

NACE: Economic Activities in the European Union

EWC: European Waste Catalogue

In nature, cannibalism refers to consuming all or part of another individual of the same species as food. One of the reasons that food webs are more connected and have higher cyclicity than eco-industrial parks (eco-parks) is the presence of cannibalism (Layton et al., 2016), which is a self-loop (Polis, 1991), in their system. In an IZ, plants using their own waste in their production processes (self-loops) may represent cannibalism (Layton et al., 2016). To evaluate the cannibalism effect on the ISNs, potential future scenarios are split into two categories; with self-loop and without selfloop.

In the first scenario, even if a plant may use its own waste as input, it does not use it and send it to another potential receiver located within the IZ. In the second scenario, if a plant may use its own waste as input, then it does so rather than sending the waste to another potential receiver. Basically, self-loop is not considered in the first scenario while it is considered in the second one. The third and fourth scenarios, which include the colocation of new plants to receive the 8 types of wastes, are an extension of the first and second scenario and build upon them respectively. In other words, adding 
future plants to Scenario 1 creates Scenario 3 and adding the same future plants to Scenario 2 creates Scenario 4. Consequently, self-loop is not considered in the third scenario while it is considered in the forth one. Figure 5 shows scenario creation steps using the symbiosis database for specific waste $k$ produced by (a) plant(s) located within the IZ. 


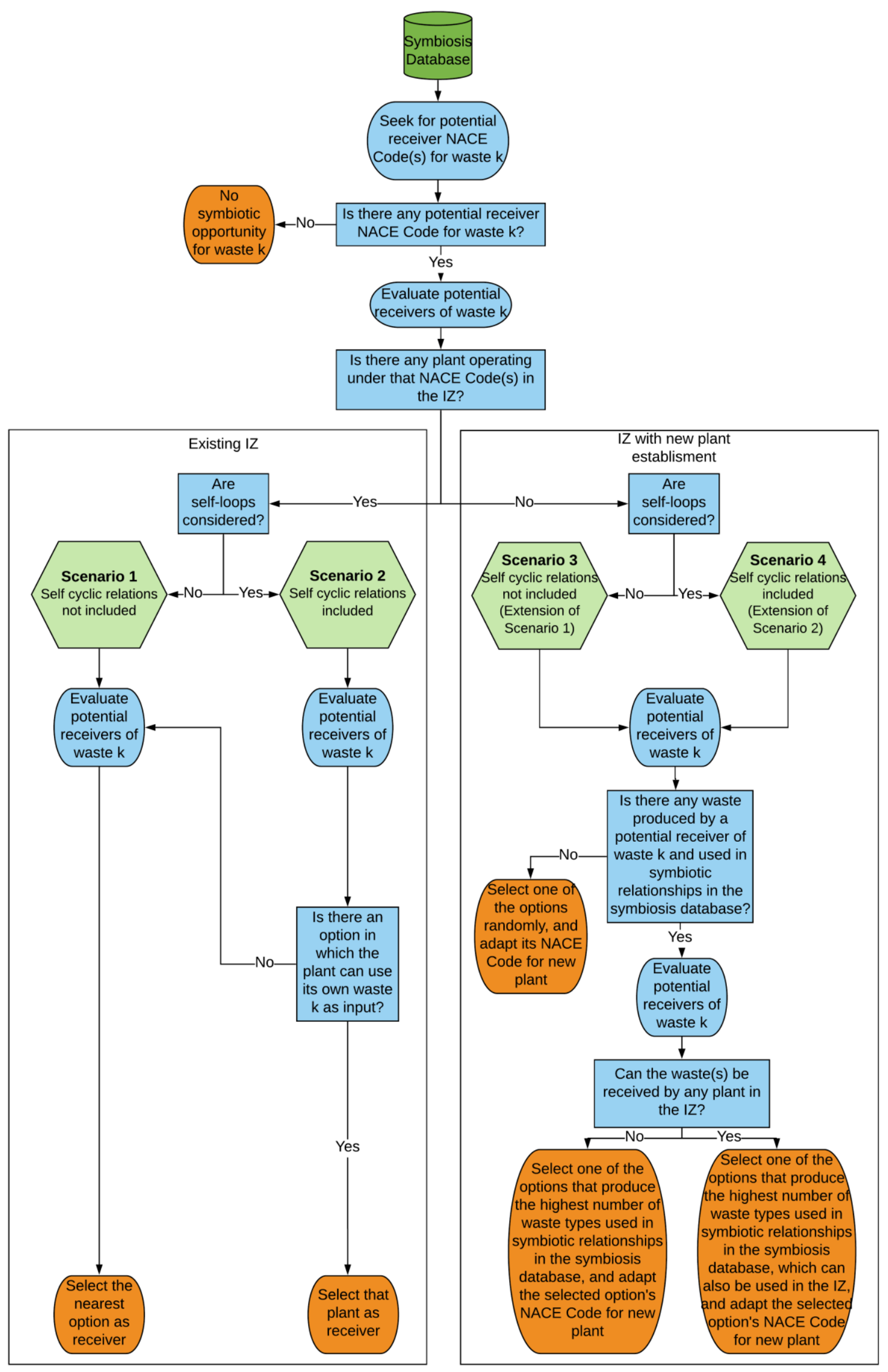

Fig. 5. Scenario creation steps using symbiosis database for specific waste $k$ 
All scenarios have multiple potential receiver options. Geographic proximity affects the transportation cost proportional to the distance between the provider and supplier in any business transaction (Lombardi and Laybourn, 2012). Hence, as wastes typically have a low economic value and options of IS might range over longer distances, exchanges realizable within larger distances are expected to be economically unfeasible (Lowe and Evans, 1995).

To make a potential receiver selection for Scenario 1 and 2, the distances between the waste producer and potential waste receiver options are identified for each symbiotic relationship opportunities on Google Maps. When the distances are calculated, the shortest path between the producer and potential receiver plants are measured. Then the nearest option is selected. Note that the shortest paths represent the current existing roads used by vehicles within the IZ.

For Scenario 3 and 4, which include the colocation of new plants to receive the 8 types of wastes mentioned above, besides being receivers, if possible, the potential future plants are wanted to play a second role as waste producers in the potential symbiotic relationships within the IZ. Therefore, among the options of potential future plants, the ones that do not only receive those 8 types of wastes but also produce other waste(s) that can be used by industrial plants located within the IZ are intended to be selected. The potential symbiotic relationships related to the potential future plants are also identified from the symbiosis database. Consequently, when the future potential receiver options of those 8 types of wastes are evaluated, the one that also produces the highest number of waste types used in the symbiotic relationships in the symbiosis database, which can also be used within the IZ, is selected. If there is no such an option, then the one that produces the highest number of any type of wastes used in the symbiotic relationships in the symbiosis database is selected. This will create other future options for symbiotic relationships within the IZ. If none of these two options is present, then a random selection is made among potential options. If it is the only option, making a random selection among potential waste receiver options do not have any effect on calculations. Because, the randomly selected option will only receive one of those 8 types of wastes produced by (a) plant(s) within the IZ, and will not produce any type of waste that can be used within the IZ network. So, it is not relevant for calculations that the specific waste is received by a future plant named A or B. Table 2 shows the information about the selected future plants and potential NACE codes that can receive waste from them. The details of scenario related symbiotic relationships can be found in Supporting Information-S3.

Table 2. Future plants and potential NACE codes that can receive wastes from them

\begin{tabular}{lll}
\hline Future Plant Given Name & Future Plant NACE Code & $\begin{array}{l}\text { Industries (by NACE Codes) That Can } \\
\text { Receive Waste(s) From Future Plants }\end{array}$ \\
\hline A100 & 32.40 & - \\
C100 & 24.40 & - \\
D100 & 17.12 & $17.11 / 20.15$ \\
E100 & 10.39 & $10.39 / 22.29 / 35.21 / 38.21$ \\
G100 & 42.11 & - \\
H100 & 32.99 & - \\
I100 & 17.10 & $20.11 / 20.14 / 23.51 / 35.11$ \\
K100 & 17.29 & - \\
\hline NACE: Economic Activities in the European Union
\end{tabular}




\section{RESULTS}

This section presents the analysis of the IZ network. Firstly, the base case is addressed with results from both the food web analysis (FWA) and social network analysis (SNA). This is followed by a comparison of all four potential future scenarios with the base case.

\subsection{Base Case}

This section presents the results of FWA and SNA for the base case. Firstly, FWA results are provided. This is followed by the presentation of SNA results.

\subsubsection{FWA Results}

A food web matrix $[\mathrm{F}]$ for the base case is created and then the food web metrics are calculated based on the $[\mathrm{F}]$. Table 3 shows the results of these food web metrics. There is a relatively high prey to predator ratio $\left(\mathrm{P}_{\mathrm{r}}\right)$ of 7,5 , i.e., the 4 key plants $\left(\mathrm{N}_{\text {Predator }}=4\right)$ absorb wastes produced by 30 plants $\left(\mathrm{N}_{\text {Prey }}=30\right)$ within the IZ. The metrics vulnerability $(\mathrm{V})$ and generalization $(\mathrm{G})$ are found to score 1,067 and 8 respectively. This means that on average each prey (waste producer) is consumed by 1,067 predators (waste receivers) and each predator consumes 8 preys. Connectance (C) and link density $\left(\mathrm{L}_{\mathrm{D}}\right)$ values are considerably lower than the theoretical maximum values they can be (both values are $<\% 1$ of max. theoretical possible value). The cyclicity value $\lambda_{\max }$ is 0 , stating that there is no cyclic pathway (closed-loop) within the IZ.

Table 3. Food web metrics calculated from food web matrix $[\mathrm{F}]$ of the base case

\begin{tabular}{llllllllll}
\hline $\begin{array}{l}\text { Species } \\
(\mathbf{S R})\end{array}$ & $\begin{array}{l}\text { Links } \\
\left(\mathbf{N}_{\mathbf{L}}\right)\end{array}$ & $\begin{array}{l}\text { Predator } \\
\left(\mathbf{N}_{\text {predator }}\right)\end{array}$ & $\begin{array}{l}\text { Prey } \\
\left(\mathbf{N}_{\text {prey }}\right)\end{array}$ & $\begin{array}{l}\text { Connectance } \\
\text { without } \\
\text { cannibalism } \\
(\mathbf{C})\end{array}$ & $\begin{array}{l}\text { Link } \\
\text { Density }\left(\mathbf{L}_{\mathbf{D}}\right)\end{array}$ & $\begin{array}{l}\text { Prey/Predator } \\
\text { Ratio } \\
(\mathbf{P r})\end{array}$ & $\begin{array}{l}\text { Vulnerability } \\
(\mathbf{V})\end{array}$ & $\begin{array}{l}\text { Generalization } \\
(\mathbf{G})\end{array}$ & $\begin{array}{l}\text { Cyclicity } \\
\left(\lambda_{\max }\right)\end{array}$ \\
\hline 58 & 32 & 4 & 30 & 0,009679371 & 0,551724138 & 7,5 & 1,066666667 & 8 & 0 \\
\hline
\end{tabular}

Note: The value of $\mathrm{C}$ is calculated with the formula presented in Equation 10 as none of the relations contains a self-loop in the base case. 

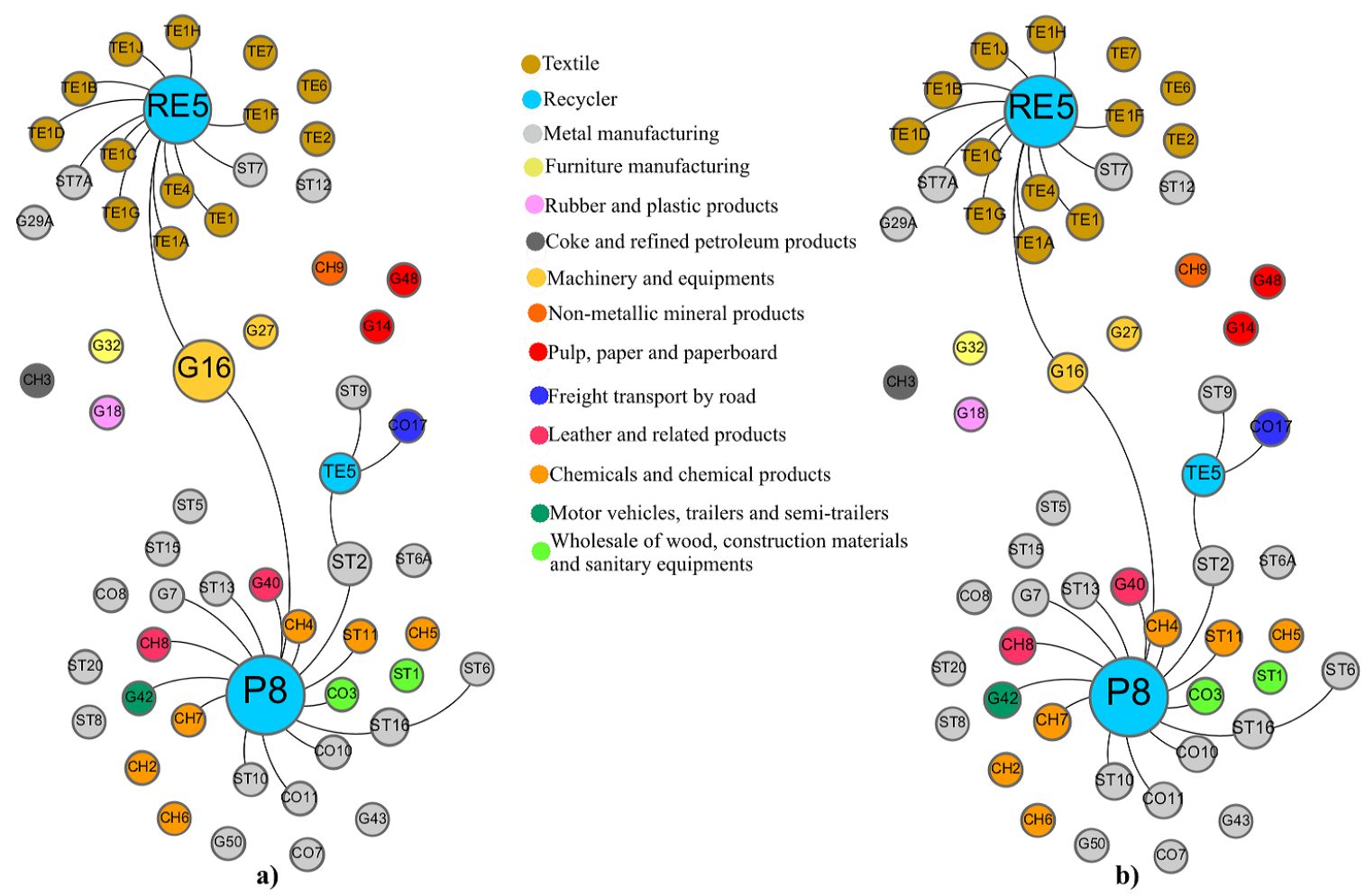

Fig. 6. The centrality of plants in the base case a) Betweenness centrality, and b) Degree centrality. Note: The waste flow direction (from producer to receiver) is indicated by the clockwise direction of a graph (there is no anti-clockwise flow). The centrality of nodes is represented by node size.

See Supporting Information-S4 for grey scale version.

A first observation is that metal manufacturing is the leading industry in the IZ. Hence, the metal manufacturers in the IZ may play essential roles in developing IS network. Table 4 shows the centrality metrics, and node degrees of all industrial actors within the IZ with respect to waste flows realized within the IZ. Furthermore, it shows the node degrees of all industrial actors when they consider including the out of zone waste flows as well. It is obvious that Node P8 and RE5 (both are recycler plants) have the highest in-degree values ( $\left.D_{\mathrm{Nin}}\right), 15$ and 13 respectively, highlighting that 27 other plants send their wastes to these two recycler plants (note: plant G16 sends waste to both recycler). In terms of waste producers, when including the out of the IZ waste flows, DST16out (a metal manufacturing plant) stands out with a value of 25 followed by DST2out (another manufacturing plant) with the value of 22. However, $\mathrm{D}_{\text {ST16out }}$ and $\mathrm{D}_{\text {ST2out }}$ are 1 and 2 within the IZ, indicating that these plants send their wastes to one and two plants within the IZ, respectively. In terms of total degree (D), the values of $D_{\text {ST16 }}$ (a metal manufacturing plant) and $D_{P 8}$ (a recycler plant) are relatively higher, indicating that both plants have a substantial potential to take part in new IS relations. Considering the whole network of the IZ, the value of DST16 is much lower than DP8. However, the value of DP8 is primarily the result of incoming wastes.

As can be observed from Figure 6(a), the recycler plant P8 takes a central position. This is the result of P8's high betweenness centrality $\left(\mathrm{BC}_{\mathrm{P} 8}=24,937 \%\right.$.). This indicates a high potential to connect and control other plants within the IZ. Another recycler plant RE5 is a close follower with a $\mathrm{BC}_{\mathrm{RE} 5}$ value of $19,173 \% .25$ plants have 
no waste transfers at all within the IZ. Plant G16, a machinery and equipment manufacturer plant, fulfills a special role. It serves as an intermediate plant, which can help develop more connections for symbiotic relationships. However, the plant lacks the capacity such as degree centrality to stimulate IS network growth. Degree centralities within the IZ are shown in Figure 6(b). It is clear that a recycler plant P8 ranks first with a $\mathrm{DC}_{\mathrm{P} 8}$ value of $26,316 \%$, followed by another recycler plant RE5 with a $\mathrm{DC}_{\mathrm{RE} 5}$ value of $22,807 \%$. This could imply that waste utilizers have more power on waste flows than waste providers within the IZ.

Table.4 Node degrees and centrality metrics of plants in the IZ

\begin{tabular}{|c|c|c|c|c|c|c|c|c|c|}
\hline \multirow[b]{2}{*}{ No } & \multirow[b]{2}{*}{$\begin{array}{l}\text { Nodes } \\
\text { (Plants) }\end{array}$} & \multirow[b]{2}{*}{$\mathbf{D}_{\mathrm{Nin}}$} & \multicolumn{3}{|c|}{ Waste flows within IZ } & \multirow[b]{2}{*}{$\begin{array}{l}\mathrm{BC}_{\mathrm{N}} \\
(\%)\end{array}$} & \multicolumn{3}{|c|}{$\begin{array}{l}\text { Including out of IZ } \\
\text { waste flows }\end{array}$} \\
\hline & & & D $_{\text {Nout }}$ & $\mathbf{D}_{\mathrm{N}}$ & $\mathrm{DC}_{\mathrm{N}}(\%)$ & & $\mathbf{D}_{\text {in }}$ & $\mathbf{D}_{\text {out }}$ & D \\
\hline 1 & TE1 & 0 & 1 & 1 & 0,01754386 & 0 & 0 & 5 & 5 \\
\hline 2 & TE1A & 0 & 1 & 1 & 0,01754386 & 0 & 0 & 5 & 5 \\
\hline 3 & TE1B & 0 & 1 & 1 & 0,01754386 & 0 & 0 & 5 & 5 \\
\hline 4 & TE1C & 0 & 1 & 1 & 0,01754386 & 0 & 0 & 5 & 5 \\
\hline 5 & TE1D & 0 & 1 & 1 & 0,01754386 & 0 & 0 & 5 & 5 \\
\hline 6 & $\mathrm{TE} 1 \mathrm{~F}$ & 0 & 1 & 1 & 0,01754386 & 0 & 0 & 5 & 5 \\
\hline 7 & TE1G & 0 & 1 & 1 & 0,01754386 & 0 & 0 & 5 & 5 \\
\hline 8 & TE1H & 0 & 1 & 1 & 0,01754386 & 0 & 0 & 6 & 6 \\
\hline 9 & TE1J & 0 & 1 & 1 & 0,01754386 & 0 & 0 & 5 & 5 \\
\hline 10 & TE4 & 0 & 1 & 1 & 0,01754386 & 0 & 0 & 6 & 6 \\
\hline 11 & TE6 & 0 & 0 & 0 & 0 & 0 & 0 & 1 & 1 \\
\hline 12 & TE7 & 0 & 0 & 0 & 0 & 0 & 0 & 1 & 1 \\
\hline 13 & TE2 & 0 & 0 & 0 & 0 & 0 & 0 & 1 & 1 \\
\hline 14 & $\mathrm{CH} 8$ & 0 & 1 & 1 & 0,01754386 & 0 & 0 & 4 & 4 \\
\hline 15 & G40 & 0 & 1 & 1 & 0,01754386 & 0 & 0 & 8 & 8 \\
\hline 16 & G48 & 0 & 0 & 0 & 0 & 0 & 0 & 2 & 2 \\
\hline 17 & G14 & 0 & 0 & 0 & 0 & 0 & 0 & 3 & 3 \\
\hline 18 & $\mathrm{CH} 3$ & 0 & 0 & 0 & 0 & 0 & 0 & 2 & 2 \\
\hline 19 & $\mathrm{CH} 2$ & 0 & 0 & 0 & 0 & 0 & 0 & 1 & 1 \\
\hline 20 & ST11 & 0 & 1 & 1 & 0,01754386 & 0 & 0 & 1 & 1 \\
\hline 21 & $\mathrm{CH} 7$ & 0 & 1 & 1 & 0,01754386 & 0 & 0 & 4 & 4 \\
\hline 22 & $\mathrm{CH} 4$ & 0 & 1 & 1 & 0,01754386 & 0 & 0 & 3 & 3 \\
\hline 23 & CH6 & 0 & 0 & 0 & 0 & 0 & 0 & 1 & 1 \\
\hline 24 & $\mathrm{CH} 5$ & 0 & 0 & 0 & 0 & 0 & 0 & 4 & 4 \\
\hline 25 & G18 & 0 & 0 & 0 & 0 & 0 & 0 & 1 & 1 \\
\hline 26 & $\mathrm{CH} 9$ & 0 & 0 & 0 & 0 & 0 & 0 & 5 & 5 \\
\hline 27 & ST2 & 0 & 2 & 2 & 0,035087719 & 0,054511 & 0 & 22 & 22 \\
\hline 28 & ST9 & 0 & 1 & 1 & 0,01754386 & 0 & 0 & 6 & 6 \\
\hline 29 & ST6A & 0 & 0 & 0 & 0 & 0 & 0 & 1 & 1 \\
\hline 30 & ST13 & 0 & 1 & 1 & 0,01754386 & 0 & 0 & 11 & 11 \\
\hline 31 & ST8 & 0 & 0 & 0 & 0 & 0 & 0 & 2 & 2 \\
\hline 32 & ST16 & 1 & 1 & 2 & 0,035087719 & 0,019424 & 1 & 25 & 26 \\
\hline 33 & $\mathrm{CO} 8$ & 0 & 0 & 0 & 0 & 0 & 0 & 1 & 1 \\
\hline 34 & ST12 & 0 & 0 & 0 & 0 & 0 & 0 & 7 & 7 \\
\hline 35 & ST20 & 0 & 0 & 0 & 0 & 0 & 0 & 13 & 13 \\
\hline 36 & ST15 & 0 & 0 & 0 & 0 & 0 & 0 & 1 & 1 \\
\hline 37 & ST7 & 0 & 1 & 1 & 0,01754386 & 0 & 0 & 7 & 7 \\
\hline 38 & ST5 & 0 & 0 & 0 & 0 & 0 & 0 & 5 & 5 \\
\hline 39 & ST10 & 0 & 1 & 1 & 0,01754386 & 0 & 0 & 1 & 1 \\
\hline 40 & CO11 & 0 & 1 & 1 & 0,01754386 & 0 & 0 & 2 & 2 \\
\hline 41 & $\mathrm{CO} 7$ & 0 & 0 & 0 & 0 & 0 & 0 & 1 & 1 \\
\hline 42 & ST6 & 0 & 1 & 1 & 0,01754386 & 0 & 0 & 1 & 1 \\
\hline 43 & G29A & 0 & 0 & 0 & 0 & 0 & 0 & 1 & 1 \\
\hline 44 & G43 & 0 & 0 & 0 & 0 & 0 & 0 & 5 & 5 \\
\hline 45 & $\mathrm{CO} 10$ & 0 & 1 & 1 & 0,01754386 & 0 & 0 & 2 & 2 \\
\hline 46 & G50 & 0 & 0 & 0 & 0 & 0 & 0 & 1 & 1 \\
\hline 47 & G7 & 0 & 1 & 1 & 0,01754386 & 0 & 0 & 10 & 10 \\
\hline 48 & ST7A & 0 & 1 & 1 & 0,01754386 & 0 & 0 & 5 & 5 \\
\hline 49 & G16 & 0 & 2 & 2 & 0,035087719 & 0,154762 & 0 & 15 & 15 \\
\hline 50 & G27 & 0 & 0 & 0 & 0 & 0 & 0 & 7 & 7 \\
\hline 51 & G42 & 0 & 1 & 1 & 0,01754386 & 0 & 0 & 1 & 1 \\
\hline 52 & G32 & 0 & 0 & 0 & 0 & 0 & 0 & 1 & 1 \\
\hline 53 & P8 & 15 & 0 & 15 & 0,263157895 & 0,249373 & 21 & 5 & 26 \\
\hline 54 & RE5 & 13 & 0 & 13 & 0,228070175 & 0,191729 & 20 & 4 & 24 \\
\hline 55 & TE5 & 3 & 0 & 3 & 0,052631579 & 0,038221 & 4 & 4 & 8 \\
\hline 56 & ST1 & 0 & 0 & 0 & 0 & 0 & 0 & 2 & 2 \\
\hline
\end{tabular}




\begin{tabular}{cccccccc|ccc}
57 & $\mathrm{CO} 3$ & 0 & 1 & 1 & 0,01754386 & 0 & 0 & 3 & 3 \\
\hline 58 & $\mathrm{CO} 17$ & 0 & 1 & 1 & 0,01754386 & 0 & 0 & 5 & 5 \\
\hline
\end{tabular}
a self-loop in the base case.

\subsection{Evaluation of Potential Future Scenarios}

This section presents the evaluation of the four potential future scenarios compared with the base case. Firstly, the comparison of the FWA results are provided, followed by the presentation of the comparison with the SNA results.

\subsubsection{FWA Results}

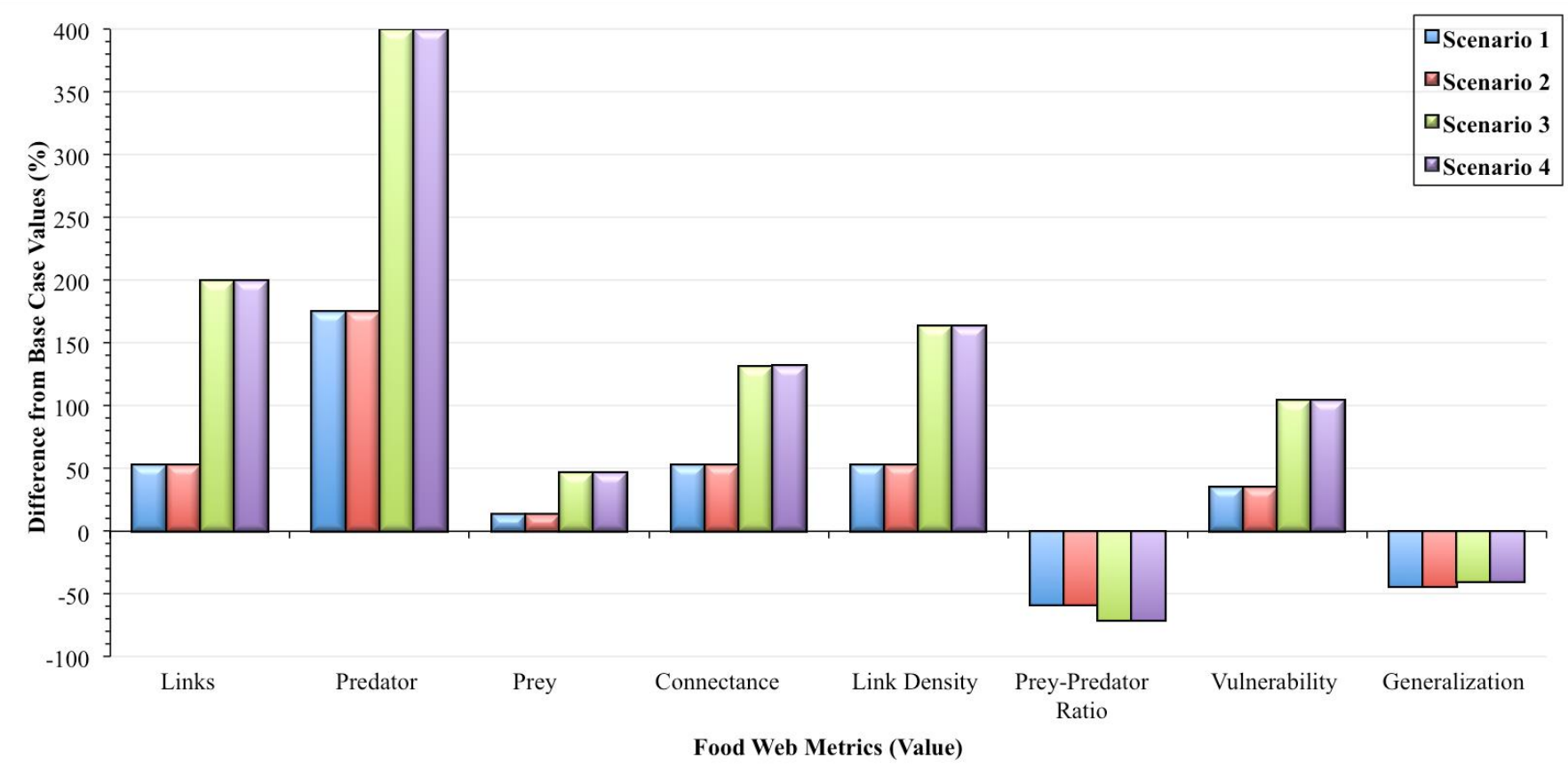

Fig. 7. Scenarios's percentage differences from the base case values for Food Web metrics. See Supporting Information-S4 for grey scale version.

Table 5 presents the food web metrics for each of the four potential future scenarios of the IZ calculated based on the each scenario's food web matrix [F]. The analysis of these results, by means of the percentage changes in food web metrics, are presented in Figure 7. The most substantial difference noted between the base case and all potential future scenarios are for the metric 'number of predator' $\left(\mathrm{N}_{\text {predator }}\right)$ and 'number of links' $\left(\mathrm{N}_{\mathrm{L}}\right)$, with a change of $175 \%$ to $400 \%$ and $53,125 \%$ to $200 \%$ difference, respectively. The results of link density $\left(\mathrm{L}_{\mathrm{D}}\right)$ and connectance $(\mathrm{C})$ metrics show also a substantial increase (from 53,125\% to $163,637 \%$ and $53,125 \%$ to $131,680 \%$ respectively). The minimum positive increase is observed on the metric 'number of prey' $\left(\mathrm{N}_{\text {prey }}\right)$ with a change of $13,333 \%$ to $46,667 \%$. That means more than half of the wastes used to establish potential future symbiotic relationships are received by recyclers in the base case. In terms of vulnerability (V), Scenario 3 and 4 (both 104,545\% difference) have a more substantial increase than Scenario 1 and 2 (both $35,110 \%$ difference). This indicates that each prey (waste producer) is consumed by more predators (waste receivers) with new plant establishment. Negative changes are observed with prey to predator ratio $\left(\mathrm{P}_{\mathrm{r}}\right)(-58,788 \%$ to - 
$70,667 \%)$ and the generalization $(\mathrm{G})(-40 \%$ to $-44,318 \%)$, which means that all potential future scenarios create more predator than prey. Table 5 shows that while Scenario 1 and 3 have no cyclicity, Scenario 2 and 4 do (value of 1), suggesting that scenarios that contain self-loop relations can introduce, although not strong, cyclic pathways within the IZ.

Table 5. Food web metrics calculated for four potential future scenarios of the IZ based on their corresponding [F]

\begin{tabular}{|c|c|c|c|c|c|c|c|c|c|c|}
\hline $\begin{array}{l}\text { Potential } \\
\text { Future } \\
\text { Scenarios }\end{array}$ & $\begin{array}{l}\text { Species } \\
\left(\mathbf{S}_{\mathbf{R}}\right)\end{array}$ & $\begin{array}{l}\text { Links } \\
\left(\mathbf{N}_{\mathrm{L}}\right)\end{array}$ & $\begin{array}{l}\text { Predator } \\
\left(\mathbf{N}_{\text {predator }}\right)\end{array}$ & $\begin{array}{l}\text { Prey } \\
\left(\mathbf{N}_{\text {prey }}\right)\end{array}$ & $\begin{array}{l}\text { Connectance } \\
\text { (C) }\end{array}$ & $\begin{array}{l}\text { Link } \\
\text { Density } \\
\left(\mathbf{L}_{\mathbf{D}}\right)\end{array}$ & $\begin{array}{l}\text { Prey/Predator } \\
\text { Ratio } \\
\text { (Pr) }\end{array}$ & $\begin{array}{l}\text { Vulnerability } \\
\text { (V) }\end{array}$ & $\begin{array}{l}\text { Generalization } \\
\text { (G) }\end{array}$ & $\begin{array}{l}\text { Cyclicity } \\
\left(\lambda_{\max }\right)\end{array}$ \\
\hline Scenario 1 & 58 & 49 & 11 & 34 & 0,0148 & 0,8448 & 3,0909 & 1,4411 & 4,4545 & 0 \\
\hline Scenario 2 & 58 & 49 & 11 & 34 & 0,0145 & 0,8448 & 3,0909 & 1,4411 & 4,4545 & 1 \\
\hline Scenario 3 & 66 & 96 & 20 & 44 & 0,0223 & 1,4545 & 2,2 & 2,1818 & 4,8 & 0 \\
\hline Scenario 4 & 66 & 96 & 20 & 44 & 0,0220 & 1,4545 & 2,2 & 2,1818 & 4,8 & 1 \\
\hline
\end{tabular}

\subsubsection{SNA Results}

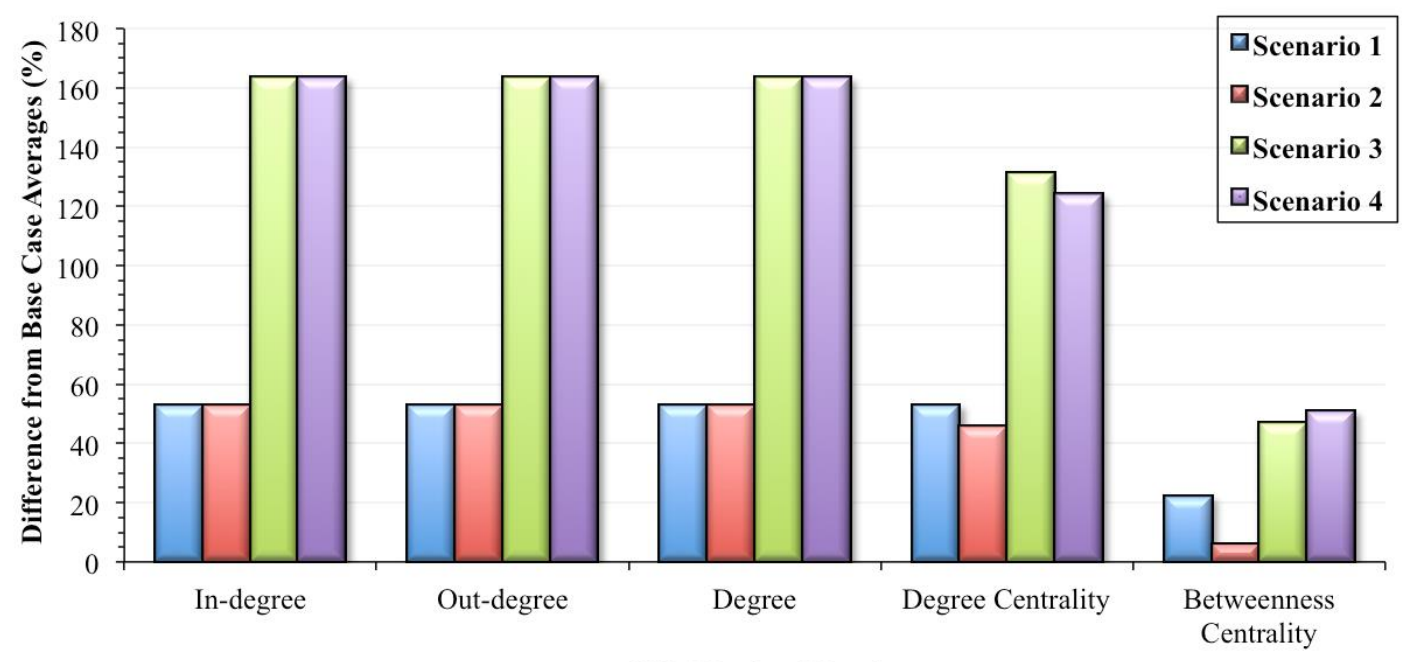

SNA Metrics (Mean)

Fig. 8. Percentage difference from the base case's averages for SNA metrics as applied to the average values for the 4 future scenarios.

See Supporting Information-S4 for grey scale version.

Figure 8 shows the percentage difference from the base case's averages for SNA metrics as applied to the average values for the four potential future scenarios. When a symbiotic relationship is established, a value of 1 is added up to the participant waste producer plant's out-degree $\left(D_{\text {Nout }}\right)$, as well as to the participant waste receiver plant's in-degree $\left(D_{\mathrm{Nin}}\right)$ and both participant plants' total degree $\left(\mathrm{D}_{\mathrm{N}}\right)$. Therefore, these 3 metrics of SNA have an equal percentage change with respect to Scenario 1 and 2 $(53,1125 \%)$, as well as Scenario 3 and $4(163,636 \%)$. In terms of degree centrality 
(DC), Scenario 3 has the highest percentage change (131,189\%), followed by Scenario $4(124,129 \%)$, Scenario 1 (53,125\%), and Scenario 2 (45,879). This indicates that potential new symbiotic relationships increase the average DC, but when self-loops are present, the average degree centrality increases less. The percentage change of average betweenness centrality (BC) is found particularly high in Scenario 4 (50,972\%), followed by Scenario 3 (46,915\%), Scenario 1 (22,213\%), and Scenario $2(6,195 \%)$. In general, average BC values decrease when a self-loop relation is established as observed in multiple cases of implementation in Scenario 1 and 2. However, the opposite is observed in cases between Scenario 3 and 4. This can be explained by the observation that some self-loop relations push some nodes to the periphery of the network. Those peripheral nodes increase the $\mathrm{BC}$ value of their firstlevel neighbor and second-level neighbor more than decreasing their own nodes's BC value. Figure 9 shows the scenario related centrality changes of different plants within the IZ. 


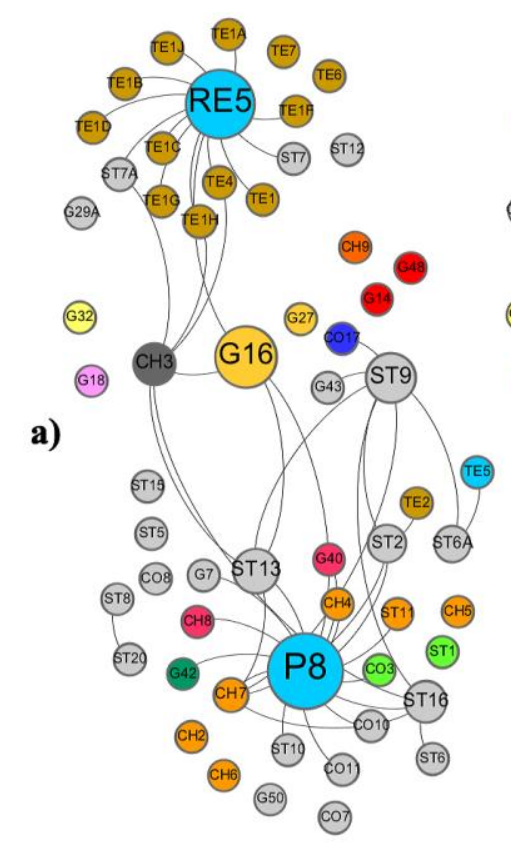

Scenario 1

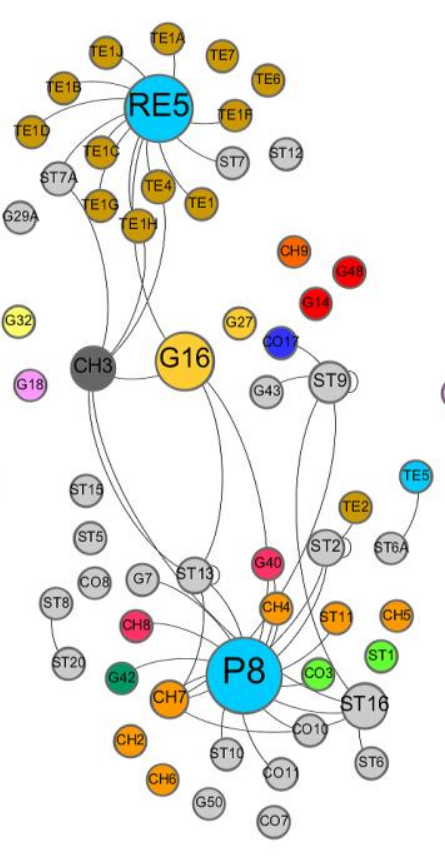

Scenario 2

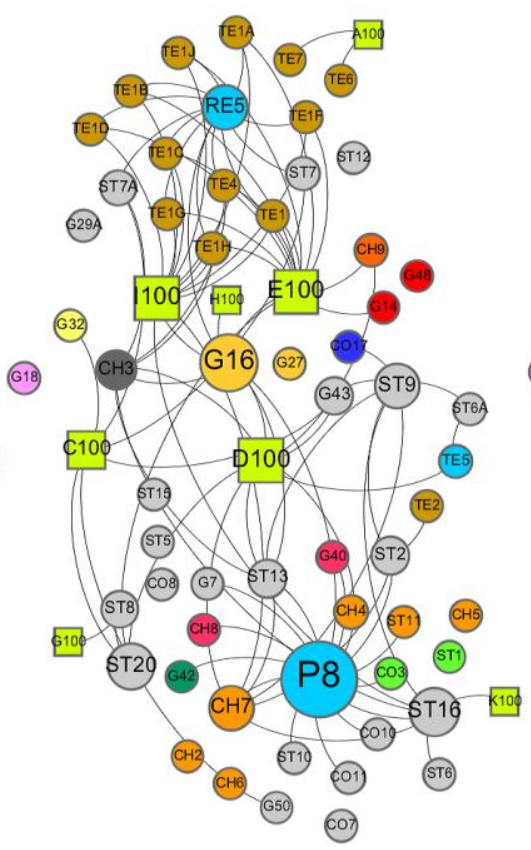

Scenario 3

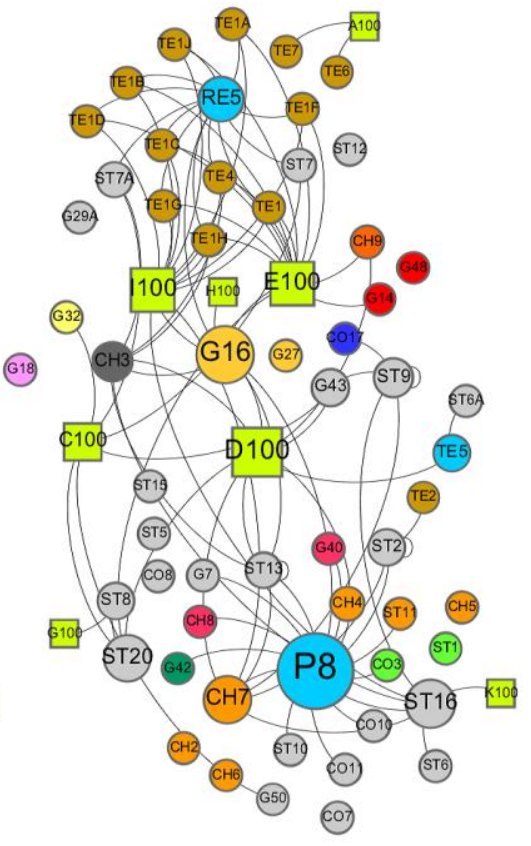

Scenario 4

Textile
Recycler
Metal manufacturing
Furniture manufacturing
Rubber and plastic products
Coke and refined petroleum products
Machinery and equipments

Non-metallic mineral products Pulp, paper and paperboard

- Freight transport by road Leather and related products Chemicals and chemical products

Motor vehicles, trailers and semi-trailers

Wholes sale of wood, construction materials and sanitary equipments New establieshed plant
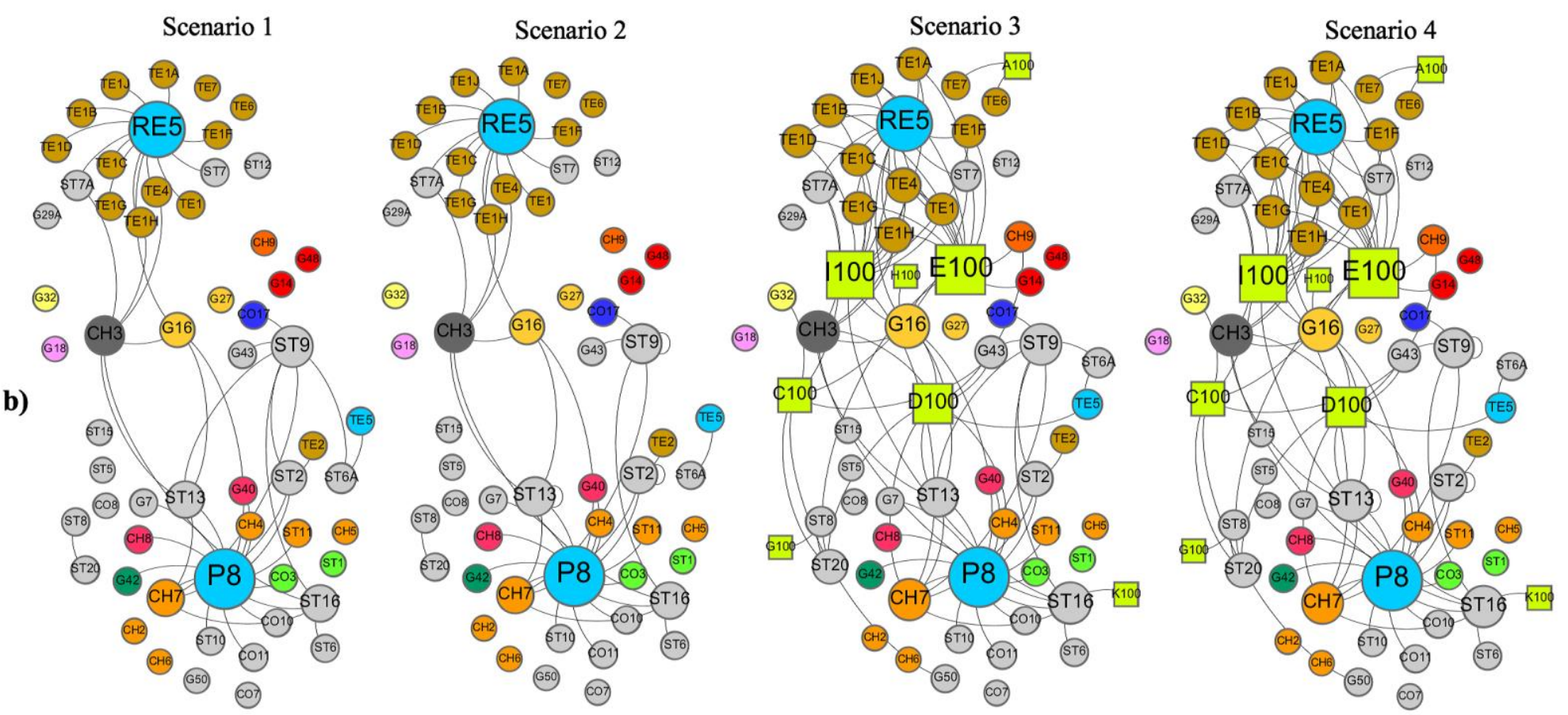

Fig. 9. Scenario related centrality changes of different plants in the IZ a) Betweenness centrality, and b) Degree centrality

Note: The waste flow direction (from producer to receiver) is indicated by the clockwise direction of a graph (there is no anti-clockwise flows). The centrality of nodes is represented by node size.

See Supporting Information-S4 for grey scale version. 


\section{DISCUSSION}

This sections discusses the effect of integrating FWA and SNA as a method to evaluate the resilience, redundancy, connectance and cyclicity of IZs, which are the important industrial symbiosis network (ISN) design measurements (Dunne et al., 2002; Wu et al., 2017; Zhu and Ruth, 2013).

\subsection{Resilience and Redundancy}

Resilience is the capability of a system to absorb internal and external disruptions while maintaining its function and structure (Allenby and Fink, 2005). Vulnerability is perceived as an antonym to resilience, and a system with higher vulnerabilities will unavoidably have lower resilience (Holling, 2001). Betweenness centrality (BC) and degree centrality (DC) are measures to determine a node's (plant's) importance in the network and the system's vulnerability (Chopra and Khanna, 2014). A network with higher overall $\mathrm{BC}$ and DC may be considerable as less vulnerable and more resilient. However, if the high BC and DC values of the network depend on a few critical nodes or edges, this resilience may turn to vulnerability if the critical node or edge is removed. Comparing with the base case, SNA results of all potential future scenarios show decreases in vulnerability arising from single nodes of failure. Classifying and shielding the plants that are broadly linked and have a high volume of waste flows in an ISN as well as increasing connectivity between plants are necessary to insure resilience to unknown disruptions. Incremental heterogeneity of critical plants may also lead to a decrease in vulnerability and increase in multifunctionality of an IS network (Chopra and Khanna, 2014). The results also disclose an increase in the number of participating plants in symbiotic businesses and the interactions among them. This situation is most evident in Scenario 3 and 4 where additions of diverse industries are established. Although self-loop relations do not affect food web metrics except for cyclicity, as it is seen in Figure 9, it has a negative effect on BC values of the plants with self-loop relations. Self-loop relations also have a negative impact on the average values of $\mathrm{BC}$ and $\mathrm{DC}$ within the IZ except for average $\mathrm{BC}$ values between scenario 3 and 4. It is clear in Figure 9 that most of the newly established plants have higher BC and DC scores than most of the existing plants. This indicates that most of the new plants have more ability than most of the existing plants to use wastes produced within the IZ in their production processes and also to send their wastes to another plants located within the IZ. This may attract the enterprisers to open a new plant within the IZ.

Redundancy in IS can be defined as duplication of critical elements and functions of an ISN (Wu et al., 2017). In ISNs, the higher the number of participants for a specific waste, the higher the resilience to disruptions in the long period will be, but the lower the economic benefits arising from the IS practice in the short run because of the additional transaction costs (Yazan et al., 2016). The results highlight that the IZ tends to have a few plants acting as the consumers of wastes for the rest of the tenant plants in the base case. Consequently, the average number of links per predator $(\mathrm{G})$ is substantially higher in the base case than in all potential future scenarios. Compared to Scenarios 1 and 2, each plant in Scenario 3 and 4 have more connections to other plants in the network $\left(\mathrm{L}_{\mathrm{D}}\right)$ and there are more plants that provide waste (prey) than plants within the network that use those wastes (predator) for all potential future scenarios, as seen in the prey to predator ratio $\left(\mathrm{P}_{\mathrm{r}}\right)$. Scenarios with new plant 
establishments increase the number of predators (waste receivers) more than the other scenarios, expressing that new plants do not only receive wastes, but also produce wastes that can be received by plants located within the IZ. From a biological food web point of view, an increase in the number of predators may be perceived as a negative impact, as predators mean enemy to preys and competitor to other predators fed upon the same species. From an industrial point of view, this depends on the participant plant's position in a symbiotic relationship, such as while it may be perceived as a positive effect for preys (waste producers) because they will have more option to send their wastes, it may not mean the same thing for predators (waste receivers) as they will need to compete with more rivals to receive the same type of waste. From an overall perspective, competition between potential waste receivers may seem to be a good strategy to create a stable waste marketplace, but it might also have a negative impact on enterprisers such as not willing to open a new plant within an IZ that needs to cope with high competition for same types of wastes.

\subsection{Connectance and Cyclicity}

Connectance and cyclicity are particularly important design metrics that show the overall structure, complexity, robustness, and internal cycling of a network (Dunne et al., 2002; Layton et al., 2013). Decomposers (e.g., bacteria and fungi) increase the connectance and cyclicity in natural ecosystems by breaking down the dead organic matter of plants and animals and move back to the ecosystem via detritivores and then carnivores. From an industrial point of view, recyclers may play decomposers role (Reap, 2009). There are three recycler plants located within the IZ. As shown in Figure 9, two recycler plants, RE5 and P8, have high DC and BC values in the base case and in all potential future scenarios. However, connectance values (C) do not show substantial changes between potential future scenarios and do not equally correlate with those recyclers' BC and DC values. Layton et al. (2013) calculated the average food web metric values for 55 biological food webs, which have the detrital (recycling) component, and found average connectance $(\mathrm{C})$ value as 0.2 and average cyclicity $\left(\lambda_{\max }\right)$ value as 4,99 . All $\mathrm{C}$ values calculated for the base case and for four potential future scenarios are also much lower than biological averages mentioned above. This indicates that the recycler plants operating within the IZ do not perform all the tasks of the decomposers living in a natural ecosystem, such as sending the wastes back to the plants within the IZ after treatment. Most of the waste produced by tenant plants that are converted into IS relationships in scenario 1 and 2 are previously sent to recyclers located out of the IZ in the base case. This may indicate that the recyclers operating within the IZ have not the technology to treat those wastes. If this is the case, improving the recyclers within the IZ or adding new recyclers that have the ability to treat those wastes produced by plants within the IZ would improve the connectance within the IZ.

Cyclicity is mainly crucial for the creation of industrial ecosystems as it exhibits the main objective for industrial ecosystems: closed-loop manufacturing (Bras et al., 2016). Cyclicity $\left(\lambda_{\max }\right)$ values show positive changes in potential future scenarios with self-loop. Self-cyclic relations move the system from non-cyclical to weak cyclical system. However, these improvements are relatively small in contrast to experiences with natural ecosystems. Hence, there is still a considerate development for these symbiotic networks to go in order to transform into an efficient and resilient state equal to those of nature's systems. Closed-loop relations between plants are still 
needed to obtain strong cyclicity $\left(\lambda_{\max }>1\right)$ within the IZ. It is most unlikely that strong cyclicity values similar to those of food webs' can be obtained in IZs without recyclers' functional roles like decomposers. Therefore, eco-park designers should integrate correspondent cooperation in symbiotic networks to accomplish more connectivity and strong cyclicity.

\section{CONCLUSION}

Because the overarching concept of network sustainability is derived through assessing sustainability from the perspective of ecological structures as well as from the aspect of social structure, it is of interest to understand the relationships between the two. Interpreting the results from the FWA and SNA together provides such new type of insight allowing one to analyze how the ecological changes might affect the social structure and vice versa in different scenarios. The FWA component substantially improves the insights into ecological network sustainability (such as comparing the symbiotic networks to the natural ecological systems they wish to mimic). The results of the ecological food web metrics study show that eco-parks created by potential future scenarios follow some sustainable properties of natural ecosystems through their symbiotic relationships (e.g., trough increasing the connectance values and improving networks from non-cyclic network to weak-cyclic network). The component of SNA improves insights into the sociological aspect of the sustainability of an industrial network. The study shows that results of the exploratory SNA analysis show adequacy to identify the important actors in a symbiotic network in accordance with their centrality values. The case study results suggest that this approach strengthens the ability to address if a new park configuration is able to retain the environmental, economic and social benefits over time.

The theoretical contribution of this study is in the form of a case study to the IS knowledge base in which the case illustrates how a set of 14 IS implementations strengthen the sustainability of an IS network, hence supporting its transformation to an eco-park. Two methodological contributions are provided; (1) based on special criteria, a decision flow chart that generalize a method for identifying and selecting potential future IS implementations and (2) the integration of FWA and SNA that provide new insights by enabling a combined interpretation on the results from both methods to assess the sustainability of IS networks. These contributions provide practitioners and policy-makers with a tool for decision making in eco-park development with respect to the identification and selection of IS implementation to maximize the environmental gain and resilience of the IS networks.

The case adopted in this paper analyses only the symbiosis networks related to waste in material form. Future work focuses on application of FWA and SNA on the symbiotic networks related to water, energy, and service with inclusion of both quantitative and qualitative data.

\section{Acknowledgments}

Our deep gratitude is extended to the Scientific and Technological Research Council of Turkey (TUBITAK) for financing this study by a grant (2214-A, International 
Research Fellowship Programme). We also thank to the Eastern Mediterranean Development Agency (DOGAKA) for supporting this study.

\section{REFERENCES}

Afshari, H., Farel, R., Peng, Q., 2018. Challenges of value creation in Eco-Industrial Parks (EIPs): A stakeholder perspective for optimizing energy exchanges.

Resour. Conserv. Recycl. 139, 315-325. https://doi.org/10.1016/J.RESCONREC.2018.09.002

Allenby, B., Fink, J., 2005. Toward inherently secure and resilient societies. Science 309, 1034-6. https://doi.org/10.1126/science.1111534

Allenby, B.R., Cooper, W.E., 1994. Understanding industrial ecology from a biological systems perspective. Environ. Qual. Manag. 3, 343-354. https://doi.org/10.1002/tqem.3310030310

Ashton, W., 2008. Understanding the Organization of Industrial Ecosystems. J. Ind. Ecol. 12, 34-51. https://doi.org/10.1111/j.1530-9290.2008.00002.x

Barrat, A., Barthélemy, M., Pastor-Satorras, R., Vespignani, A., 2004. The architecture of complex weighted networks. Proc. Natl. Acad. Sci. 101, 37473752. https://doi.org/10.1073/PNAS.0400087101

Benyus, J.M., 2002. Biomimicry: Innovation Inspired by Nature. Perennial.

Boons, F., Chertow, M., Park, J., Spekkink, W., Shi, H., 2017. Industrial Symbiosis Dynamics and the Problem of Equivalence: Proposal for a Comparative Framework. J. Ind. Ecol. 21, 938-952. https://doi.org/10.1111/jiec.12468

Borgatti, S.P., Mehra, A., Brass, D.J., Labianca, G., 2009. Network analysis in the social sciences. Science 323, 892-5. https://doi.org/10.1126/science.1165821

Bras, B., Layton, A., Weissburg, M., 2016. Improving Performance of Eco-Industrial Parks, in: Sustainable Design and Manufacturing. pp. 227-240. https://doi.org/10.1007/978-3-319-32098-4_20

Buys, L., Mengersen, K., Johnson, S., van Buuren, N., Chauvin, A., 2014. Creating a Sustainability Scorecard as a predictive tool for measuring the complex social, economic and environmental impacts of industries, a case study: Assessing the viability and sustainability of the dairy industry. J. Environ. Manage. 133, 184192. https://doi.org/10.1016/J.JENVMAN.2013.12.013

Chertow, M., Ehrenfeld, J., 2012. Organizing Self-Organizing Systems: Toward a Theory of Industrial Symbiosis. J. Ind. Ecol. 16, 13-27. https://doi.org/10.1111/j.1530-9290.2011.00450.x

Chertow, M.R., 2007. "Uncovering” industrial symbiosis. J. Ind. Ecol. 11-30. https://doi.org/10.1162/jiec.2007.1110

Chertow, M.R., 2000. Industrial symbiosi: Literature and taxonomy. Annu. Rev. energy Environ. 25, 313-337. https://doi.org/10.1146/annurev.energy.25.1.313

Chopra, S.S., Khanna, V., 2014. Understanding resilience in industrial symbiosis networks: Insights from network analysis. J. Environ. Manage. 141, 86-94. https://doi.org/10.1016/J.JENVMAN.2013.12.038

Côté, R.P., Cohen-Rosenthal, E., 1998. Designing eco-industrial parks: a synthesis of some experiences. J. Clean. Prod. 6, 181-188. https://doi.org/10.1016/S09596526(98)00029-8

Domenech, T., Davies, M., 2009. The social aspects of industrial symbiosis: the application of social network analysis to industrial symbiosis networks. Prog. Ind. Ecol. An Int. J. 6, 68. https://doi.org/10.1504/PIE.2009.026583

Dunne, J.A., Williams, R.J., Martinez, N.D., 2002. Food-web structure and network 
theory: The role of connectance and size. Proc. Natl. Acad. Sci. U. S. A. 99, 12917-22. https://doi.org/10.1073/pnas.192407699

Ehrenfeld, J., Gertler, N., 1997. Industrial Ecology in Practice: The Evolution of Interdependence at Kalundborg. J. Ind. Ecol. 1, 67-79. https://doi.org/10.1162/jiec.1997.1.1.67

Evans, S., Benedetti, M., \& Holgado Granados, M., 2017. Library of Industrial Symbiosis case studies and linked exchanges. https://doi.org/https://doi.org/10.17863/CAM.12608

Everett, M.G., Borgatti, S.P., 1999. The centrality of groups and classes. J. Math. Sociol. 23, 181-201. https://doi.org/10.1080/0022250X.1999.9990219

Fath, B.D., Halnes, G., 2007. Cyclic energy pathways in ecological food webs. Ecol. Modell. 208, 17-24. https://doi.org/10.1016/J.ECOLMODEL.2007.04.020

Freeman, L.C., 1977. A Set of Measures of Centrality Based on Betweenness. Sociometry 40, 35. https://doi.org/10.2307/3033543

Golbeck, J., 2015. Introduction to Social Media Investigation, Introduction to Social Media Investigation. https://doi.org/10.1016/B978-0-12-801656-5.00015-9

Gotelli, N.J., Colwell, R.K., 2001. Quantifying biodiversity: procedures and pitfalls in the measurement and comparison of species richness. Ecol. Lett. 4, 379-391. https://doi.org/10.1046/j.1461-0248.2001.00230.x

Graedel, T.E., 1996. ON THE CONCEPT OF INDUSTRIAL ECOLOGY. Annu. Rev. Energy Environ. 21, 69-98. https://doi.org/10.1146/annurev.energy.21.1.69

Grant, G.B., Seager, T.P., Massard, G., Nies, L., 2010. Information and Communication Technology for Industrial Symbiosis. J. Ind. Ecol. 14, 740-753. https://doi.org/10.1111/j.1530-9290.2010.00273.x

Hardy, C., Graedel, T.E., 2002. Industrial Ecosystems as Food Webs. J. Ind. Ecol. 6, 29-38. https://doi.org/10.1162/108819802320971623

Holling, C.S., 2001. Understanding the Complexity of Economic, Ecological, and Social Systems. Ecosystems 4, 390-405. https://doi.org/10.1007/s10021-0010101-5

Kossinets, G., Watts, D.J., 2006. Empirical analysis of an evolving social network. Science (80-. ). 311, 88-90. https://doi.org/10.1126/science.1116869

Kuznetsova, E., Zio, E., Farel, R., 2016. A methodological framework for EcoIndustrial Park design and optimization. J. Clean. Prod. 126, 308-324. https://doi.org/10.1016/J.JCLEPRO.2016.03.025

Layton, A., Bras, B., Reap, J., Weissburg, M., 2013. Biologically Inspired Closed Loop Manufacturing Networks, in: Volume 2B: Advanced Manufacturing. ASME, p. V02BT02A025. https://doi.org/10.1115/IMECE2013-63958

Layton, A., Bras, B., Weissburg, M., 2017. Improving performance of eco-industrial parks. Int. J. Sustain. Eng. 10, 250-259. https://doi.org/10.1080/19397038.2017.1317874

Layton, A., Bras, B., Weissburg, M., 2016. Industrial Ecosystems and Food Webs: An Expansion and Update of Existing Data for Eco-Industrial Parks and Understanding the Ecological Food Webs They Wish to Mimic. J. Ind. Ecol. 20, 85-98. https://doi.org/10.1111/jiec.12283

Layton, A.C., 2014. Food webs: Realizing biological inspiration for sustainable industrial resource networks.

Lombardi, D.R., Laybourn, P., 2012. Redefining Industrial Symbiosis. J. Ind. Ecol. 16, 28-37. https://doi.org/10.1111/j.1530-9290.2011.00444.x

Lowe, E.A., Evans, L.K., 1995. Industrial ecology and industrial ecosystems. J. Clean. Prod. 3, 47-53. https://doi.org/10.1016/0959-6526(95)00045-G 
M. Bastian, S. Heymann, M.J. et al., 2009. Gephi: an open source software for exploring and manipulating networks, in: Proceedings of International AAAI Conference on Web and Social Media. pp. 361-362. https://doi.org/10.1136/qshc.2004.010033

Malone, S.M., Weissburg, M.J., Bras, B., 2018. Industrial Ecosystems and Food Webs: An Ecological-Based Mass Flow Analysis to Model the Progress of Steel Manufacturing in China. Engineering 4, 209-217. https://doi.org/10.1016/J.ENG.2018.03.008

Morris, Z., Weissburg, M., Bras, B., 2018. Towards a Biologically-inspired Urbanindustrial Ecosystem. Procedia CIRP 69, 861-866. https://doi.org/10.1016/j.procir.2017.11.055

Newman, M.E.J., 2003. The Structure and Function of Complex Networks *, Society for Industrial and Applied Mathematics.

Odum, E.P., 1969. The strategy of ecosystem development. Science (80-. ). 164, $262-$ 270. https://doi.org/10.1126/science.164.3877.262

Otte, E., Rousseau, R., 2002. Social network analysis: a powerful strategy, also for the information sciences. J. Inf. Sci. 28, 441-453. https://doi.org/10.1177/016555150202800601

Paquin, R.L., Howard-Grenville, J., 2012. The Evolution of Facilitated Industrial Symbiosis. J. Ind. Ecol. 16, 83-93. https://doi.org/10.1111/j.15309290.2011.00437.x

Polis, G.A., 1991. Complex Trophic Interactions in Deserts: An Empirical Critique of Food-Web Theory. Am. Nat. 138, 123-155. https://doi.org/10.1086/285208

Reap, J., Bras, B., 2014. A Method of Finding Biologically Inspired Guidelines for Environmentally Benign Design and Manufacturing. J. Mech. Des. 136, 111110. https://doi.org/10.1115/1.4028303

Reap, J.J., 2009. Holistic biomimicry: a biologically inspired approach to environmentally benign engineering.

Sakr, D., Baas, L., El-Haggar, S., Huisingh, D., 2011. Critical success and limiting factors for eco-industrial parks: global trends and Egyptian context. https://doi.org/10.1016/j.jclepro.2011.01.001

Sebestyén, V., Bulla, M., Rédey, Á., Abonyi, J., 2019. Network model-based analysis of the goals, targets and indicators of sustainable development for strategic environmental assessment. J. Environ. Manage. 238, 126-135. https://doi.org/10.1016/J.JENVMAN.2019.02.096

Song, X., Geng, Y., Dong, H., Chen, W., 2018. Social network analysis on industrial symbiosis: A case of Gujiao eco-industrial park. J. Clean. Prod. 193, 414-423. https://doi.org/10.1016/J.JCLEPRO.2018.05.058

Tiejun, D., 2010. Two quantitative indices for the planning and evaluation of ecoindustrial parks. Resour. Conserv. Recycl. 54, 442-448. https://doi.org/10.1016/J.RESCONREC.2009.09.010

Ulanowicz, R.E., Holt, R.D., Barfield, M., 2014. Limits on ecosystem trophic complexity: insights from ecological network analysis. Ecol. Lett. 17, 127-136. https://doi.org/10.1111/ele.12216

Van Berkel, R., Fujita, T., Hashimoto, S., Geng, Y., 2009. Industrial and urban symbiosis in Japan: Analysis of the Eco-Town program 1997-2006. J. Environ. Manage. 90, 1544-1556. https://doi.org/10.1016/J.JENVMAN.2008.11.010

van Capelleveen, G., Amrit, C., Yazan, D.M., 2018. A Literature Survey of Information Systems Facilitating the Identification of Industrial Symbiosis. Springer, Cham, pp. 155-169. https://doi.org/10.1007/978-3-319-65687-8_14 
Vázquez, P., del Río, J.A., Cedano, K.G., van Dijk, J., Jensen, H.J., 2018. Network characterization of the Entangled Model for sustainability indicators. Analysis of the network properties for scenarios. PLoS One 13, e0208718. https://doi.org/10.1371/journal.pone.0208718

Vincent, J.F.V., 2017. The trade-off: a central concept for biomimetics. Bioinspired, Biomim. Nanobiomaterials 6, 67-76. https://doi.org/10.1680/jbibn.16.00005

Wright, R.A., Côté, R.P., Duffy, J., Brazner, J., 2009. Diversity and Connectance in an Industrial Context. J. Ind. Ecol. 13, 551-564. https://doi.org/10.1111/j.15309290.2009.00141.X

Wu, J., Guo, Y., Li, C., Qi, H., 2017. The redundancy of an industrial symbiosis network: A case study of a hazardous waste symbiosis network. J. Clean. Prod. 149, 49-59. https://doi.org/10.1016/J.JCLEPRO.2017.02.038

Yazan, D.M., Fraccascia, L., Albino, V., Zijm, H., 2016. Cooperation in industrial symbiosis business models: An Agent-Based Modelling approach, in: International Society for Industrial Ecology Meeting. Bogota, Colombia.

Yodzis, P., 1980. The connectance of real ecosystems. Nature 284, 544-545. https://doi.org/10.1038/284544a0

Zhang, Y., Zheng, H., Chen, B., Yang, N., 2013. Social network analysis and network connectedness analysis for industrial symbiotic systems: model development and case study. Front. Earth Sci. 7, 169-181. https://doi.org/10.1007/s11707-0120349-4

Zhu, J., Ruth, M., 2013. Exploring the resilience of industrial ecosystems. J. Environ. Manage. 122, 65-75. https://doi.org/10.1016/J.JENVMAN.2013.02.052 